\title{
Photosynthesis, Light Use Efficiency, and Yield of Reduced-Chlorophyll Soybean Mutants in Field Conditions
}

OPEN ACCESS

Edited by:

Adriano Nunes-Nesi,

Universidade Federal de Viçosa, Brazil

Reviewed by:

Christine Helen Foyer,

University of Leeds, UK

Stefan Timm,

University of Rostock, Germany

*Correspondence:

Donald R. Or

d-or@@illinois.edu

${ }^{\dagger}$ Present address:

Andy VanLoocke,

Department of Agronomy, lowa State

University, Ames, IA, USA

Specialty section:

This article was submitted to

Plant Physiology,

a section of the journal

Frontiers in Plant Science

Received: 25 October 2016

Accepted: 27 March 2017

Published: 18 April 2017

Citation:

Slattery RA, VanLoocke $A$,

Bernacchi CJ, Zhu X-G and Ort DR (2017) Photosynthesis, Light Use

Efficiency, and Yield of Reduced-Chlorophyll Soybean Mutants in Field Conditions.

Front. Plant Sci. 8:549.

doi: 10.3389/fpls.2017.00549

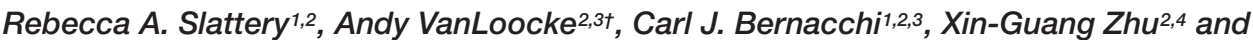 \\ Donald R. Ort $1,2,3 *$
}

\begin{abstract}
${ }^{1}$ Department of Plant Biology, University of Illinois at Urbana-Champaign, Urbana, IL, USA, ${ }^{2}$ Carl R. Woese Institute for Genomic Biology, University of Illinois at Urbana-Champaign, Urbana, IL, USA, ${ }^{3}$ Global Change and Photosynthesis Research Unit, United States Department of Agriculture, Urbana, IL, USA, ${ }^{4}$ Chinese Academy of Sciences-German Max Planck Society Partner Institute for Computational Biology, Shanghai Institutes for Biological Sciences, Chinese Academy of Sciences, Shanghai, China
\end{abstract}

Reducing chlorophyll (chl) content may improve the conversion efficiency of absorbed photosynthetically active radiation into biomass and therefore yield in dense monoculture crops by improving light penetration and distribution within the canopy. The effects of reduced chl on leaf and canopy photosynthesis and photosynthetic efficiency were studied in two reportedly robust reduced-chl soybean mutants, Y11y11 and y9y9, in comparison to the wild-type (WT) "Clark" cultivar. Both mutants were characterized during the 2012 growing season whereas only the Y11y11 mutant was characterized during the 2013 growing season. Chl deficiency led to greater rates of leaf-level photosynthesis per absorbed photon early in the growing season when mutant chl content was $\sim 35 \%$ of the WT, but there was no effect on photosynthesis later in the season when mutant leaf chl approached $50 \%$ of the WT. Transient benefits of reduced chl at the leaf level did not translate to improvements in canopy-level processes. Reduced pigmentation in these mutants was linked to lower water use efficiency, which may have dampened any photosynthetic benefits of reduced chl, especially since both growing seasons experienced significant drought conditions. These results, while not confirming our hypothesis or an earlier published study in which the Y11y11 mutant significantly outyielded the WT, do demonstrate that soybean significantly overinvests in chl. Despite a $>50 \% \mathrm{chl}$ reduction, there was little negative impact on biomass accumulation or yield, and the small negative effects present were likely due to pleiotropic effects of the mutation. This outcome points to an opportunity to reinvest nitrogen and energy resources that would otherwise be used in pigmentproteins into increasing biochemical photosynthetic capacity, thereby improving canopy photosynthesis and biomass production.

Keywords: photosynthesis, solar energy conversion efficiency, chlorophyll, canopy light distribution, soybean

\section{INTRODUCTION}

Increasing the yield potential $\left(Y_{\mathrm{p}}\right)$ of important agronomic crops is imperative for meeting predicted future production needs. $Y_{\mathrm{p}}$ is the maximum possible regional yield for a given crop in the absence of biotic and abiotic stresses (Evans and Fischer, 1999), but as radiation, water, nutrients, etc., become limiting or there is pest/pathogen pressure, realized yields decrease, 
resulting in a yield gap (Lobell et al., 2009). $Y_{\mathrm{p}}$ for a given crop during a growing season is the product of several components: the incident solar radiation across the growing season $\left(S_{t}\right)$, the proportion of $S_{\mathrm{t}}$ that is photosynthetically active radiation (PAR; estimated as 0.487$)$, the radiation interception efficiency $\left(\varepsilon_{\mathrm{i}}\right)$, the conversion efficiency of intercepted radiation into biomass $\left(\varepsilon_{\mathrm{c}}\right)$, and the partition efficiency of biomass into harvestable product $\left(\varepsilon_{\mathrm{p}}\right.$; modified from Monteith, 1977). $S_{\mathrm{t}}$ and the proportion that is PAR vary but are largely predetermined by growing season length and location, although there can be substantial interannual variability in $S_{\mathrm{t}}$ at a given location (Monteith, 1965, 1972). Of the three efficiencies, plant breeders have already pushed $\varepsilon_{\mathrm{i}}$ and $\varepsilon_{\mathrm{p}}$ near their theoretical upper limits in highly productive crops in the best years (Evans, 1993; Hay, 1995; Sinclair, 1998). Breeding in soybean (Glycine max Merr.) has achieved $\varepsilon_{i}$ season averages of approximately 0.60-0.75 (Koester et al., 2014) with peak midseason $\varepsilon_{\mathrm{i}}$ of $>0.90$ in modern cultivars (Dermody et al., 2008; Koester et al., 2014). $\varepsilon_{\mathrm{p}}$ has reached values of 0.60 for soybean (Dermody et al., 2008; Koester et al., 2014), which is at or near the estimated theoretical maximum of $\sim 0.55-0.67$ for major food crops (Austin et al., 1980; Bugbee and Monje, 1992; Khush, 1995; Smil, 1999; Hay and Porter, 2006; Prasad et al., 2006). These advancements in $\varepsilon_{\mathrm{i}}$ and $\varepsilon_{\mathrm{p}}$ leave only modest potential for further improvement of $Y_{\mathrm{p}}$ (Zhu et al., 2010). However, $\varepsilon_{\mathrm{c}}$ operates substantially below the theoretical maxima for $C_{3}(0.094)$ and $C_{4}(0.123$; Zhu et al., 2010) crop canopies and therefore limits yield potential (Zhu et al., 2008, 2010), especially in soybean where the maximum realized $\varepsilon_{\mathrm{c}}(0.028)$ is estimated at less than a third of the $C_{3}$ theoretical potential (Slattery and Ort, 2015).

Reducing leaf chlorophyll (chl) content has been proposed as a strategy to improve $\varepsilon_{\mathrm{c}}$ in crop canopies. At low light levels, leaf photosynthesis $\left(A_{\text {leaf }}\right)$ in crops such as soybean responds linearly to light intensity, but at approximately $25 \%$ of full sunlight, or $500 \mu \mathrm{mol} \mathrm{m} \mathrm{m}^{-2} \mathrm{~s}^{-1}$ photosynthetic photon flux density (PPFD), the linear relationship between absorbed quanta and $A_{\text {leaf }}$ begins to plateau (Long et al., 2006). Light in excess of photosynthetic capacity is then wasted through heat dissipation, or photoprotection, which reduces light use efficiency (Niyogi, 1999; Ort, 2001). At normal chl levels, individual soybean leaves absorb approximately $85-90 \%$ of incident PPFD, which results in the uppermost $\sim 25 \%$ of the canopy absorbing $\sim 75 \%$ of incoming light (Campbell and Norman, 1998), much of which is wasted due to light saturation of photosynthesis in these leaves. Meanwhile, at full sunlight, leaves below the uppermost 25\% receive half or less of the light needed to saturate $A_{\text {leaf }}$ and are therefore light limited (Long et al., 2006). By distributing light more proportionately throughout leaf layers (Zhu et al., 2010; Ort et al., 2011, 2015), absorbed PPFD could be used more efficiently by mitigating both light oversaturation at the top of canopy and light limitation within the canopy. It is likely that some crops overinvest in chl content to the detriment of light distribution in the canopy similar to the manner in which soybean overinvest in leaf area (Srinivasan et al., 2016). Therefore, decreasing leaf absorbance (leaf $f_{a b s}$ ) through reduced chl content seems a potential strategy to achieve deeper light penetration into a crop canopy; thus, sun leaves would absorb only enough photons at mid-day to sustain maximum $A_{\text {leaf }}$ while allowing more light to reach the lower canopy and stimulate $A_{\text {leaf }}$ in shade leaves, thereby potentially improving canopy photosynthesis $\left(A_{\mathrm{can}}\right), \varepsilon_{\mathrm{c}}$, and $Y_{\mathrm{p}}$. Experimental evidence supporting the principle of this notion has been found in similar or greater rates of $A_{\text {leaf }}$ in various crops with substantial reductions in chl compared to their dark-green counterparts (Highkin et al., 1969; Benedict et al., 1972; Edwards et al., 1993; Habash et al., 1994; Li et al., 2013; Kirst et al., 2017). In soybean, greater rates of $A_{\text {leaf }}$ on an absorbed photon basis were evident in light-green soybean leaves, and the increase in $A_{\text {leaf }}$ correlated with a more even light distribution among chloroplasts within leaves (Slattery et al., 2016). An analogous alteration of light distribution could therefore occur among leaves within a canopy. In addition, dense mass cultures of truncated light antennae $(t l a)$ green algae mutants demonstrated increased light penetration and improved solar energy conversion efficiency (Melis, 1999; Polle et al., 2002; Mitra and Melis, 2008), which ultimately led to increased hydrogen production (Kosourov et al., 2011).

Decreasing chl content could also have other benefits at the canopy level. Reducing light absorption and thereby increasing albedo at the top of the canopy could decrease leaf temperature $\left(T_{\text {leaf }}\right)$ in the upper canopy, similar to the manner in which paraheliotropism reduces $T_{\text {leaf }}$ in other species (Gamon and Pearcy, 1989). During times of above optimal temperatures, this should increase $A_{\text {leaf }}$ by mitigating negative heat stress effects (Ainsworth and Ort, 2010) and in turn also improve water use efficiency (WUE). Cooler soybean canopies lower vapor pressure deficit, resulting in higher WUE (Baldocchi et al., 1985), which was reported for alfalfa with reduced chl content compared to the full green control (Estill et al., 1991). Greater light availability with depth in the canopy could also increase WUE by facilitating greater $A_{\text {leaf }}$ in deeper layers where humidity is higher and therefore vapor pressure deficit is lower (Drewry et al., 2014; Ort and Long, 2014). If monoculture crops are overinvesting in chl biosynthesis, reallocation of nitrogen from an excess of pigment-protein complexes to other nitrogenlimited photosynthesis-related molecules might also be a benefit of chl reduction. In a modeling study, reallocating nitrogen resources among Calvin cycle enzymes predicted increased potential $A_{\text {leaf }}$ without any additional nitrogen (Zhu et al., 2007). If nitrogen that would otherwise be used in pigment and pigment-proteins were reinvested in increased photosynthetic capacity, a similar increased nitrogen use efficiency would be expected.

Soybean is the world's third most economically important commodity crop (FAO, 2012). At agricultural planting densities, soybean develops a dense canopy with a leaf area index (LAI) often greater than six. This creates a situation in which the majority of leaves are experiencing light levels below the light compensation point during most daylight hours and makes it an ideal candidate crop for testing the effects of reduced chl content on $\varepsilon_{\mathrm{c}}$. A large number of chl-deficient mutants have been identified in soybean, and two chl-deficient soybean mutants with robust canopy growth, Y11y11 and y9y9, were previously reported to have greater $A_{\text {can }}$ compared to 
the nearly isogenic "Clark" wild-type (WT) throughout the growing season (Pettigrew et al., 1989). These mutants display a disproportionately large truncation in the antennae associated with photosystem II (PSII) compared to photosystem I (PSI; Ghirardi and Melis, 1988). This leads to higher chl $a / b$ and PSII/PSI ratios, the latter of which serves to balance light absorption between the two photosystems (Eskins et al., 1983; Ghirardi and Melis, 1988). However, comprehensive studies of reduced chl effects on soybean at both the leaf and canopy scale have not yet been conducted in the same experiment. Therefore, the same light-green soybean mutants and the WT control were grown in the field during the 2012 growing season. The following year only the Y11y11 mutant was grown with the WT so that a row spacing treatment could be added. These field experiments were used to characterize the light-green mutants and to investigate the impact that reducing chl content has on leaf and canopy photosynthesis, photosynthetic efficiency, and yield.

\section{MATERIALS AND METHODS}

\section{Site Description}

Field experiments were conducted at the SoyFACE global change research facility at the University of Illinois at UrbanaChampaign $\left(40^{\circ} 02^{\prime} \mathrm{N}, 88^{\circ} 14^{\prime} \mathrm{W}, 228 \mathrm{~m}\right.$ above sea level) during the 2012 and 2013 growing seasons. The soil at this site is a deep and fertile Flanagan (fine, montmorillonitic, mesic aquic Argiudoll) with some low-lying blocks of Drummer [typic Haplaquoll; Rogers et al., 2004]. The site maintained a yearly maize-soybean rotation, and no nitrogen fertilizer was added prior to soybean planting in accordance with standard regional practices.

The experimental design consisted of a randomized complete block design with three replicates. WT soybean cultivar "Clark" and two nearly isogenic chl-deficient mutants, Y11y11 and y9y9 (Eskins et al., 1981), were grown in 2012. Only WT and Y11y11 were grown in 2013 in order to accommodate a row spacing treatment. Plots in 2012 consisted of 16-2.74 m rows running north-south with a row spacing of $0.38 \mathrm{~m}$. Planting density was 30 plants $\mathrm{m}^{-2}$. In 2013, a row spacing treatment was introduced by replicating the same design but adding a narrower row spacing treatment $(0.19 \mathrm{~m}$ between rows $)$ while maintaining a plant density of 30 plants $\mathrm{m}^{-2}$ (Supporting Information Figure S1). Since the Y11y11 genotype segregates (1 dark green: 2 light green: 1 yellow plant), it was planted at a higher density to account for the removal of Y11Y11 dark green and the seedling lethal y11y11 yellow plants before determining the final plant density. Planting in 2012 occurred on 16 May [day of year (DOY) 137], and harvest occurred on 17 October (DOY 291). In 2013, seeds were sown in the $0.38 \mathrm{~m}$ row spacing treatment on 7 June (DOY 158) with a cone planter. The narrow row spacing treatment was planted 1 day later on 8 June (DOY 159) with a push-planter. All plants were harvested on 11 October (DOY 284). Daily meteorological data spanning the growing season (planting to harvest) were obtained from the Illinois Climate Network monitoring station $\sim 1.5 \mathrm{~km}$ from the field site (Table 1 and Figure 1; Angel, 2009).

\section{Gas Exchange Measurements Diurnal Leaf Gas Exchange}

All leaf gas exchange measurements were conducted with open path gas exchange systems equipped with leaf chamber fluorometers (LI-6400, LI-COR, Lincoln, NE, USA). Diurnal gas exchange measurements (5-6 time points at $2 \mathrm{~h}$ intervals throughout the day) were conducted six times during the 2012 growing season and five times during 2013 on sun leaves. A diurnal was conducted on shade leaves after canopy closure in 2012 as well. Sun leaves were designated as the youngest, fully expanded leaves exposed to full sunlight throughout the day. Shade leaves were designated as 3-4 nodes below the sun leaf on the same plant. Measurement chamber conditions were set to ambient PPFD and $60-70 \%$ relative humidity. For shade leaves, PPFD was measured within the canopy using a $1 \mathrm{~m}$ long quantum sensor (LI-190, LI-COR, Lincoln, NE, USA) before each set of measurements. The sensor was inserted into the canopy at the height of the shade leaves and at multiple locations within each block. The average light level across all blocks within each genotype was then used for that time point. Block temperature of the gas exchange system was set to ambient air temperature, and reference $\mathrm{CO}_{2}$ concentration $\left(\left[\mathrm{CO}_{2}\right]\right.$ ) was set to $400 \mathrm{ppm}$. The daily integral of $A_{\text {leaf }}\left(A^{\prime}\right)$ was determined as in Rogers et al. (2004) for each replicate, after which statistical analyses were conducted (see below). Daily means of $A_{\text {leaf, }} g_{s}$, intrinsic water use efficiency (iWUE; calculated as $A_{\text {leaf }} / g_{s}$ for each point measurement before statistically analyzing as described below), and $T_{\text {leaf }}$ (measured by the LI-6400 LI-COR, Lincoln, NE, USA) were also determined for sun leaves.

\section{Light Response of Leaf Photosynthesis}

Photosynthetic light response $(A / Q)$ curves were conducted on sun leaves in the field at midday during the V5 (five true leaves) developmental stage in 2012 and during the V5, R1/R2 (flowering), and R5 (pod filling) developmental stages (Fehr et al., 1971) in 2013. Shade leaf $A / Q$ measurements were only conducted in 2013 after canopy closure (R1/R2 and R5). Sun and shade leaves were designated as described above. Curves consisted of 12 points spanning from 0 to $2000 \mu \mathrm{mol} \mathrm{m}^{-2} \mathrm{~s}^{-1}$ PPFD. Dark-adapted minimal fluorescence $\left(F_{\mathrm{o}}\right)$ and maximal fluorescence $\left(F_{\mathrm{m}}\right)$ were measured pre-dawn the same day as $A / Q$ measurements were conducted. Lightadapted steady state fluorescence $\left(F_{\mathrm{s}}{ }^{\prime}\right)$, minimal fluorescence $\left(F_{\mathrm{o}}{ }^{\prime}\right)$, and maximal fluorescence $\left(F_{\mathrm{m}}{ }^{\prime}\right)$ were measured on each leaf during $A / Q$ measurements according to Baker (2008). The operating efficiency of photosystem II ( $\phi P S I I)$ was calculated as $\left(F_{\mathrm{m}}{ }^{\prime}-F_{\mathrm{s}}\right) / F_{\mathrm{m}}{ }^{\prime}$ and non-photochemical quenching $(N P Q)$ was calculated as $\left(F_{\mathrm{m}}-F_{\mathrm{m}}{ }^{\prime}\right) / F_{\mathrm{m}}{ }^{\prime}$. The electron transport rate through PSII $(E T R)$ was calculated as PPFD* Leaf ${ }_{\text {abs }}{ }^{*} f_{\text {PSII }} * \phi P S I I$ where $f_{\text {PSII }}$ is the fraction of absorbed PPFD that goes to PSII (Baker, 2008). Maximum rate of photosynthesis $\left(A_{\text {sat }}\right)$ was determined by fitting a non-rectangular curve to the data (SigmaPlot, Systat Software Inc., San Jose, CA, USA). Maximum quantum efficiency $\left(\phi \mathrm{CO}_{2}\right)$ was determined as the slope of the linear fit of $A_{\text {leaf }}$ versus absorbed PPFD (Proc Reg; SAS 9.4, SAS Institute, Cary, NC, USA) at low light using data from light levels at or above the light compensation point to avoid any potential effects on the 
TABLE 1 | Meteorological conditions during the 2012 and 2013 soybean growing seasons (planting to harvest) in Champaign, IL, USA.

\begin{tabular}{|c|c|c|c|c|c|c|c|c|c|}
\hline Year & $\begin{array}{c}\text { Row } \\
\text { space }(m)\end{array}$ & $\begin{array}{l}\text { Planting } \\
\text { date }\end{array}$ & $\begin{array}{l}\text { Emergence } \\
\text { date }\end{array}$ & $\begin{array}{c}\text { Harvest } \\
\text { date }\end{array}$ & $\begin{array}{l}\text { Precipitation }^{a} \\
\text { (mm) }\end{array}$ & $\begin{array}{c}T_{\max }{ }^{a} \\
\left({ }^{\circ} \mathrm{C}\right)\end{array}$ & $\begin{array}{c}T_{\min }{ }^{a} \\
\left({ }^{\circ} \mathrm{C}\right)\end{array}$ & $\begin{array}{c}T_{\text {mean }}{ }^{a} \\
\left({ }^{\circ} \mathrm{C}\right)\end{array}$ & $\begin{array}{l}\text { Solar radiation }{ }^{a} \\
\left(\mathrm{MJ} \mathrm{m}^{-2}\right)\end{array}$ \\
\hline 2012 & 0.38 & 16 May & 25 May & 17 Oct & $517^{\dagger}$ & 28.4 & 14.9 & 21.4 & 3,337 \\
\hline 2013 & 0.38 & 7 Jun & 17 Jun & 16 Oct & 271 & 28.2 & 15.7 & 21.6 & 2,396 \\
\hline 2013 & 0.19 & 8 Jun & 21 Jun & 16 Oct & 271 & 28.3 & 15.7 & 21.6 & 2,380 \\
\hline
\end{tabular}

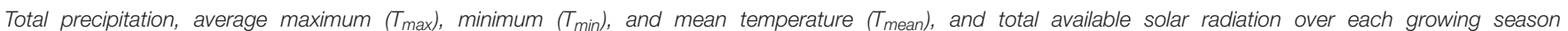

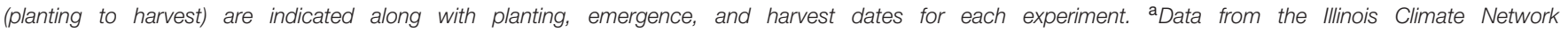

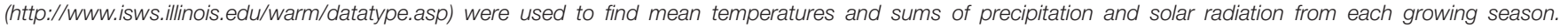

†Precipitation $(481 \mathrm{~mm})+$ two irrigations of $18 \mathrm{~mm}$ each during mid-July.

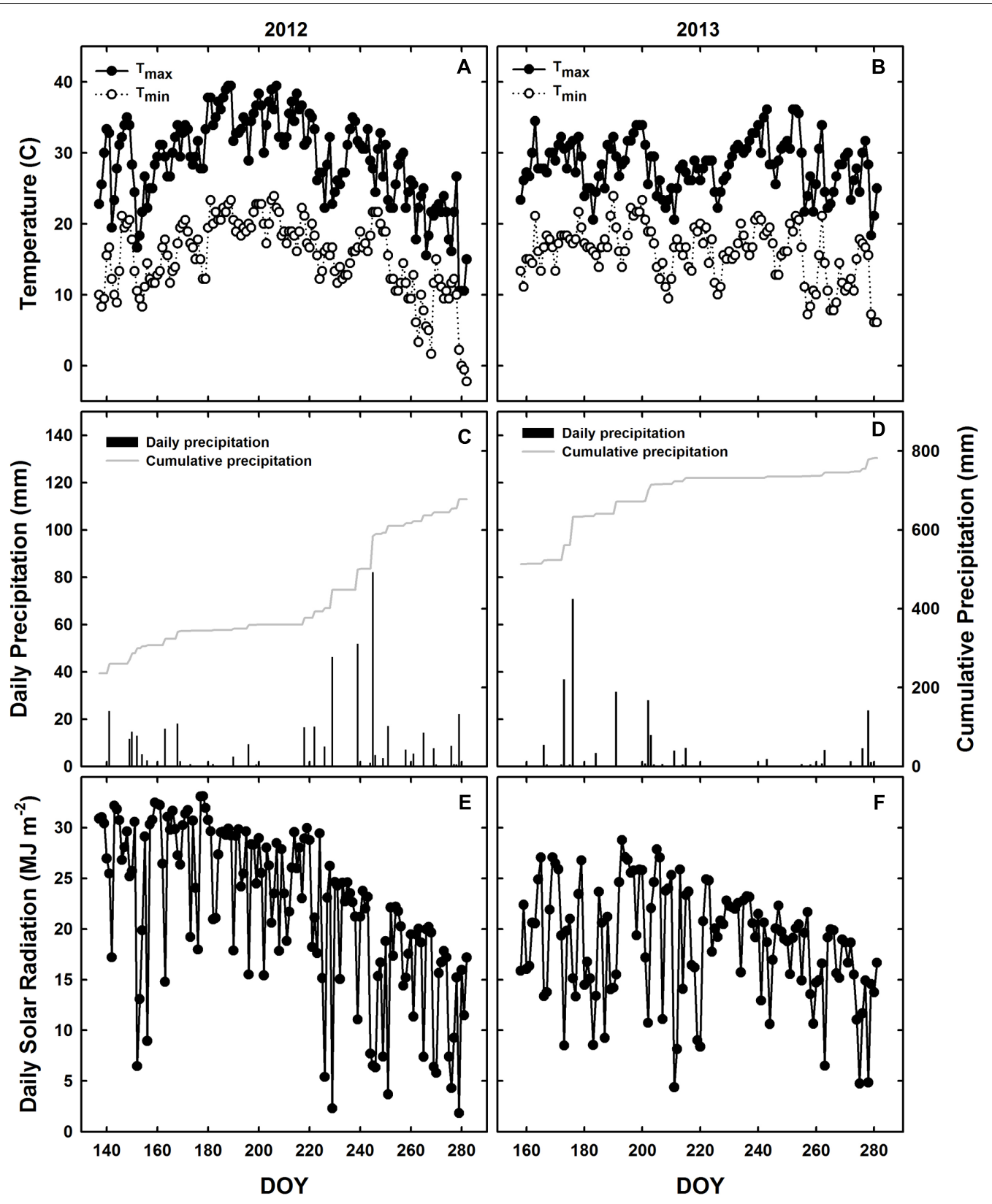

FIGURE 1 | Meteorological conditions during the 2012 and 2013 growing seasons in Champaign, IL, USA. Daily observations from 2012 (A,C,E) and 2013 $\mathbf{( B , D , F )}$ are indicated for maximum (black circles) and minimum (white circles) temperatures (A,B), daily precipitation during the growing season (black bars) and cumulative annual precipitation (gray line; C,D), and incident solar radiation (E,F). 
slope due to the Kok effect (Kok, 1948). Proc Loess (SAS 9.4; SAS Institute, Cary, NC, USA) was used to determine $90 \%$ confidence intervals for all $A / Q$ data where non-overlapping intervals indicated significant differences. The relationship between $A_{\text {sat }}$ and chl content across all genotypes and growing seasons was also plotted with a second order logarithmic function (SigmaPlot, Systat Software Inc., San Jose, CA, USA).

\section{$\mathrm{CO}_{2}$ Response of Leaf Photosynthesis}

Photosynthetic $\left[\mathrm{CO}_{2}\right]$ response $\left(\mathrm{A} / \mathrm{C}_{\mathrm{i}}\right)$ curves were conducted every 2 weeks throughout the 2012 growing season and during the V5, R1/R2, and R5 developmental stages in 2013. Measurements were conducted on sun leaves, and shade leaves were also measured in 2013 after canopy closure (R1/R2 and R5 stages). Maximum carboxylation rates of Rubisco $\left(V_{c, \max }\right)$, maximum electron transport rates $\left(J_{\max }\right)$, and the intercellular $\left[\mathrm{CO}_{2}\right]$ at the inflection point between Rubisco and RuBP limited $A_{\text {leaf }}\left(C_{\mathrm{i} \text {,inflection }}\right)$ were determined according to Long and Bernacchi (2003). $V_{c, \text { max }}$ versus chl content and $J_{\max }$ versus chl content were also plotted in the same manner as the $A_{\text {sat }}$ versus chl content relationship described above.

\section{Leaf Dark Respiration}

Dark respiration $\left(R_{\mathrm{d}}\right)$ was measured $1-3 \mathrm{~h}$ after dusk using a LI-6400 equipped with a specially designed leaf chamber able to enclose an entire trifoliate leaf (Gillespie et al., 2012). Measurements were conducted at the three developmental stages in 2013 on sun and shade leaves as described above. After measurements, leaves were detached and leaf area was measured using a leaf area meter (LI-3100, LI-COR, Lincoln, NE, USA) in order to calculate $R_{\mathrm{d}}$ on a leaf area basis.

\section{Midday Canopy Photosynthesis}

$A_{\text {can }}$ was measured at midday using a portable chamber on DOY 197 (V5), 213 (R1/R2), 221 [R3/R4 (pod initiation)], and 242 (R5) during 2013 on wide row widths planting in a manner similar to Prater et al. (2006). A chamber $(0.914 \mathrm{~m} \times 1.02 \mathrm{~m}$ base $\times 1.37 \mathrm{~m}$ height) with clear plastic siding was equipped with mixing fans and a rubber gasket on the bottom edge. An open path infrared gas analyzer (LI-7500, LI-COR, Lincoln, NE, USA) was mounted just above the canopy height within the chamber and was connected to a data logger (LI-7550, LI-COR, Lincoln, NE, USA) outside of the chamber. To reduce soil disturbance and prevent leakage during measurements, aluminum frames with vertical sides and a flat surface on top matching the dimensions of the chamber base $(0.914 \mathrm{~m} \times 1.02 \mathrm{~m})$ were inserted into the soil in the area of measurement at least 1 day before measurements. The bottom surface of the chamber was lowered onto the flat top surface of the frame, rather than the uneven soil surface, with a seal created by the rubber gasket. $\mathrm{CO}_{2}$ drawdown was measured on the two rows of plants encompassed within the chamber within 1 min of lowering the chamber over the canopy and onto the frames to minimize any microclimate effects. Soil respiration was measured using an infrared gas analyzer equipped with a soil $\mathrm{CO}_{2}$ flux chamber (LI-6400-09, LI-COR, Lincoln, NE, USA). Soil respiration measurements were conducted in two locations within the measured $A_{\text {can }}$ area within $1 \mathrm{~h}$ prior to or immediately following the chamber measurements to account for any changes in $\left[\mathrm{CO}_{2}\right]$ within the chamber due to soil $\mathrm{CO}_{2}$ flux. One row of plants from within the chamber area was used for biomass harvests (see below), and total leaf area within the chamber was estimated from those measurements. Canopy $\mathrm{CO}_{2}$ assimilation rates were calculated after accounting for soil respiration rates and adjusted to a leaf area basis.

\section{Leaf Tissue Sampling and Biomass Harvests}

\section{Leaf Tissue Sampling}

Leaf disks $2 \mathrm{~cm}$ in diameter were collected at midday during each diurnal and dried to determine specific leaf weight (SLW; $\mathrm{g} \mathrm{m}^{-2}$ ). Leaf disks $1 \mathrm{~cm}$ in diameter were collected at midday during each diurnal to determine chl content, chl $a / b$ ratios, and total carotenoid content using the methods of Lichtenthaler (1987) and Porra et al. (1989). Near the end of the 2013 season during developmental stage $\mathrm{R} 5,2 \mathrm{~cm}$ leaf disks were taken from leaves at the top (uppermost $0.25 \mathrm{~m})$, middle $(0.25-0.50 \mathrm{~m}$ from the top of the canopy), and bottom (0.50-0.75 m from the top of the canopy) of the canopy to determine integrated WUE using isotope analyses (Farquhar and Richards, 1984). The samples were dried and ground to a powder, after which an elemental analyzer (Elemental Combustion System 4010, Costech Analytical Technologies, Inc., Valencia, CA, USA) in parallel with an isotope ratio mass spectrometry system (Finnigan Delta V Advantage Mass Spectrometer, Thermo Fisher Scientific, Waltham, MA, USA) were used to determine $\delta^{13} \mathrm{C}$ on a per mass basis.

\section{Leaf Absorbance Measurements}

Leaf $_{\text {abs }}$ was measured during the three developmental stages of 2013 at various heights within the canopy using an integrating sphere (Spectroclip-JAZ-TR, Ocean Optics, Duiven, The Netherlands). Leaf $f_{\text {abs }}$, or the fraction of light absorbed, was calculated as

$$
\text { Leaf }_{\mathrm{abs}}=I_{\mathrm{o}}-I_{\mathrm{t}}-I_{\mathrm{r}}
$$

where $I_{\mathrm{o}}$ is incident radiation, $I_{\mathrm{t}}$ is transmitted radiation, and $I_{\mathrm{r}}$ is reflected radiation. Absorbance of the blue $(460 \mathrm{~nm})$ and red $(635 \mathrm{~nm})$ wavelengths emitted from LEDs within the open gas exchange chambers (LI-6400, LI-COR, Lincoln, NE, USA) was used to calculate total absorbed PPFD during $A / Q$ measurements. Since leaf $f_{\text {abs }}$ was not measured in 2012, the relationships between chl content and blue and red light absorbance from 2013 (Supporting Information Figure S2) were used to estimate absorbed PPFD during $2012 \mathrm{~A} / \mathrm{Q}$ measurements.

\section{Biomass Determination}

Aboveground biomass harvests were conducted every 10-14 days each season by harvesting $1 \mathrm{~m}$ of a row in each plot at soil height while avoiding plot borders or previous harvest locations. Plant height was measured on three of the plants, and the number of plants per meter of row was recorded. Leaf area per plant was determined for five plants in each plot using a leaf area meter (LI-3100, LI-COR, Lincoln, NE, USA) and adjusted for total plant 


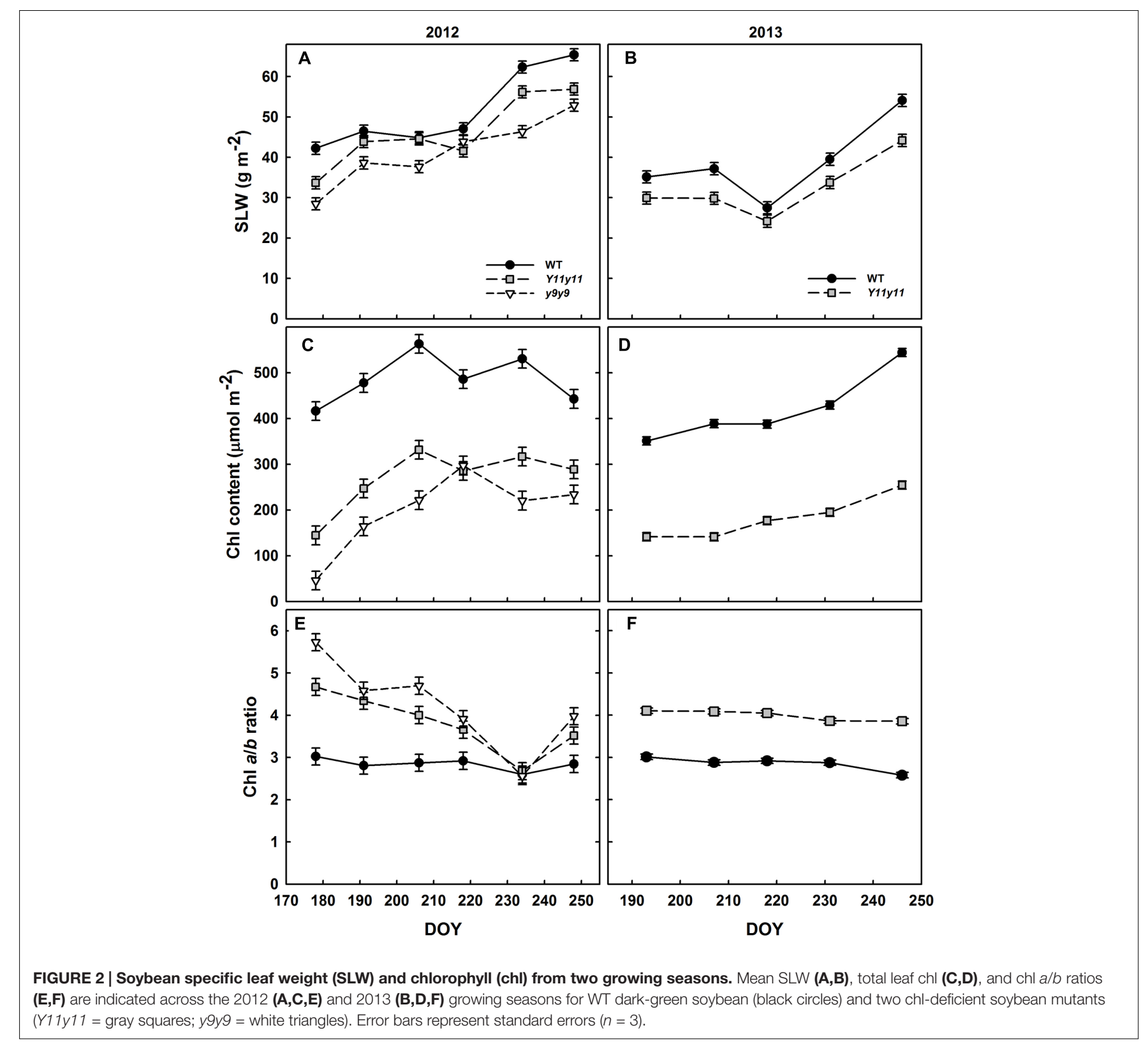

number to determine total leaf area within the canopy chamber (see above). Stems, leaves, and pods were then separated and dried at $65-70^{\circ} \mathrm{C}$ for 3 days to determine dry weights. Stem and leaf dry weights were converted to MJ of energy per land area using the tissue-specific energy contents from Amthor et al. (1994). Pod energy at various reproductive stages was determined in 2013 using a bomb calorimeter with a benzoic acid standard (Model 1261, Parr Instrument, Moline, IL, USA). This was used to convert pod mass to pod energy on a land area basis for each reproductive stage after pod initiation in both 2012 and 2013.

\section{$\varepsilon_{\mathrm{i}}, \varepsilon_{\mathrm{c}}, \varepsilon_{\mathrm{p}}$, and Yield}

Daily canopy light interception fraction and season-long interception efficiency, $\varepsilon_{\mathrm{i}}$, were determined as the fraction of available PAR that was absorbed (APAR) by the canopy. APAR was calculated as

$$
\operatorname{APAR}=I_{\mathrm{o}}-\left(I_{\mathrm{t}}+I_{\mathrm{r}}\right)
$$

where $I_{\mathrm{o}}$ was incident PAR measured above the canopy with an upright quantum sensor, $I_{\mathrm{t}}$ was transmitted PAR measured at soil level using a line sensor, and $I_{\mathrm{r}}$ was reflected PAR measured with an inverted quantum sensor above the canopy. All data were collected using line (model SQ-311) and quantum (model SQ-110) sensors (Apogee Instruments, Logan, UT, USA) that had been calibrated with a high precision quantum sensor (LI-190, LI-COR, Lincoln, NE, USA) at the beginning of the season. All data were logged every $10 \mathrm{~s}$ using a datalogger (model CR3000 in 2012 and model CR10X in 2013, Campbell Scientific, 
TABLE 2 | Light- and dark-green soybean leaf pigment and physiological parameters from two growing seasons and two leaf levels.

\begin{tabular}{|c|c|c|c|c|c|c|c|c|c|}
\hline \multirow{3}{*}{$\frac{\text { Leaf }}{\text { Sun }}$} & \multirow{2}{*}{\multicolumn{2}{|c|}{ Parameter }} & \multicolumn{4}{|c|}{2012} & \multicolumn{3}{|c|}{2013} \\
\hline & & & \multirow{2}{*}{$\begin{array}{c}\text { WT } \\
51.4\end{array}$} & \multirow{2}{*}{$\begin{array}{c}\text { Y11y11 } \\
46.1^{*}\end{array}$} & \multirow{2}{*}{$\begin{array}{c}y 9 y 9 \\
41.3^{*}\end{array}$} & \multirow{2}{*}{$\begin{array}{c}\text { MSE } \\
0.78\end{array}$} & \multirow{2}{*}{$\begin{array}{c}\text { WT } \\
38.7\end{array}$} & \multirow{2}{*}{$\begin{array}{c}\text { Y11y11 } \\
32.4^{*}\end{array}$} & \multirow{2}{*}{$\frac{\text { MSE }}{0.61}$} \\
\hline & SLW & $\left(\mathrm{g} \mathrm{m}^{-2}\right)$ & & & & & & & \\
\hline & Chl content & $\left(\mu \mathrm{mol} \mathrm{m}{ }^{-2}\right)$ & 486 & $269 *$ & $197^{*}$ & 13 & 420 & $182^{*}$ & 4.9 \\
\hline & $\mathrm{Chl} a / b$ & - & 2.84 & $3.81^{*}$ & $4.24^{*}$ & 0.065 & 2.85 & 3.99* & 0.036 \\
\hline & Carotenoids & $\left(\mathrm{g} \mathrm{m}^{-2}\right)$ & 59.3 & $40.1^{*}$ & $35.3^{*}$ & 2.5 & 55.3 & $35.6^{*}$ & 1.0 \\
\hline & Leaf $_{a b s}$ & - & - & - & - & - & 0.86 & $0.72^{*}$ & 0.58 \\
\hline & $A^{\prime}$ & $\left(\mathrm{mol} \mathrm{m} \mathrm{m}^{-2} \mathrm{~d}^{-1}\right)$ & 0.787 & $0.854^{*}$ & $0.758^{*}$ & 0.011 & 0.834 & 0.832 & 0.006 \\
\hline & $A_{\text {leaf }}$ & $\left(\mu \mathrm{mol} \mathrm{m} \mathrm{m}^{-2} \mathrm{~s}^{-1}\right)$ & 18.1 & $19.6^{*}$ & 17.5 & 0.26 & 20.3 & 20.3 & 0.15 \\
\hline & $g_{\mathrm{s}}$ & $\left(\mathrm{mol} \mathrm{H}_{2} \mathrm{O} \mathrm{m}^{-2} \mathrm{~s}^{-1}\right)$ & 0.225 & $0.268 *$ & $0.300 *$ & 0.014 & 0.641 & $0.796^{*}$ & 0.011 \\
\hline & iWUE & $\left(\mu \mathrm{mol} \mathrm{mol}{ }^{-1}\right)$ & 95.9 & 87.5 & $73.0^{*}$ & 3.5 & 35.0 & $27.5^{*}$ & 0.34 \\
\hline & $T_{\text {leaf }}$ & $\left({ }^{\circ} \mathrm{C}\right)$ & 29.8 & 29.4 & 29.0 & 0.081 & 23.9 & 23.4 & 0.057 \\
\hline & $V_{\mathrm{c}, \max }$ & $\left(\mu \mathrm{mol} \mathrm{m} \mathrm{m}^{-2} \mathrm{~s}^{-1}\right)$ & 121 & 127 & 116 & 3.3 & 107 & 106 & 3.5 \\
\hline & $J_{\max }$ & $\left(\mu \mathrm{mol} \mathrm{m} \mathrm{m}^{-2} \mathrm{~s}^{-1}\right)$ & 162 & 167 & 158 & 2.8 & 166 & $178^{*}$ & 3.3 \\
\hline & $C_{i, \text { inflection }}$ & $\left(\mu \mathrm{mol} \mathrm{mol}{ }^{-1}\right)$ & 187 & 176 & 182 & 6.5 & 182 & $233^{*}$ & 15 \\
\hline & $A_{\text {sat }}$ & $\left(\mu \mathrm{mol} \mathrm{m} \mathrm{m}^{-2} \mathrm{~s}^{-1}\right)$ & 33.2 & $47.4^{*}$ & 28.6 & 4.3 & 34.5 & 32.6 & 0.52 \\
\hline & $\phi \mathrm{CO}_{2}$ & - & 0.068 & 0.061 & $0.036^{*}$ & 0.00004 & 0.054 & 0.061 & 0.005 \\
\hline & $R_{\mathrm{d}}$ & $\left(\mu \mathrm{mol} \mathrm{m} \mathrm{m}^{-2} \mathrm{~s}^{-1}\right)$ & - & - & - & - & -1.26 & $-1.10^{*}$ & 0.027 \\
\hline \multirow[t]{9}{*}{ Shade } & Chl content & $\left(\mu \mathrm{mol} \mathrm{m}{ }^{-2}\right)$ & 558 & $242^{*}$ & $105^{*}$ & 20 & 395 & $168^{*}$ & 21 \\
\hline & Chl $a / b$ & - & 2.27 & $3.26^{*}$ & $4.46^{*}$ & 0.15 & 2.67 & $3.37^{*}$ & 0.16 \\
\hline & $A^{\prime}$ & $\left(\mathrm{mol} \mathrm{m} \mathrm{m}^{-2} \mathrm{~d}^{-1}\right)$ & 0.174 & 0.194 & 0.185 & 0.016 & - & - & - \\
\hline & $V_{\mathrm{c}, \max }$ & $\left(\mu \mathrm{mol} \mathrm{m} \mathrm{m}^{-2} \mathrm{~s}^{-1}\right)$ & - & - & - & & 122 & 97.2 & 5.7 \\
\hline & $J_{\max }$ & $\left(\mu \mathrm{mol} \mathrm{m} \mathrm{m}^{-2} \mathrm{~s}^{-1}\right)$ & - & - & - & & 188 & 164 & 15 \\
\hline & $C_{i, \text { inflection }}$ & $\left(\mu \mathrm{mol} \mathrm{mol}{ }^{-1}\right)$ & - & - & - & & 206 & 247 & 27 \\
\hline & $A_{\text {sat }}$ & $\left(\mu \mathrm{mol} \mathrm{m} \mathrm{m}^{-2} \mathrm{~s}^{-1}\right)$ & - & - & - & & 30.9 & 27.2 & 3.5 \\
\hline & $\phi \mathrm{CO}_{2}$ & - & - & - & - & & 0.060 & 0.060 & 0.004 \\
\hline & $R_{\mathrm{d}}$ & $\left(\mu \mathrm{mol} \mathrm{m} \mathrm{m}^{-2} \mathrm{~s}^{-1}\right)$ & - & - & - & & -0.655 & -0.542 & 0.060 \\
\hline
\end{tabular}

Growing season means are reported for variables related to physical leaf properties, diurnal measurements, photosynthetic response curves, and dark respiration rates.

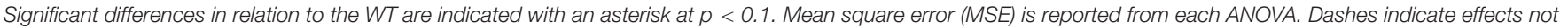
measured.

Logan, UT, USA). Measurements began on DOY 180 in 2012 and DOY 189 in 2013 and corresponded to the V5 developmental stage. The energy conversion efficiency $\left(\varepsilon_{c}\right)$ was determined as the slope of accumulated aboveground biomass energy regressed on accumulated APAR from early vegetative stages to peak biomass energy. $\varepsilon_{\mathrm{p}}$ was determined as the ratio of seed energy: total aboveground plant energy at harvest maturity. Yield and seed mass were determined after harvesting and threshing seeds from pods of four complete rows per plot in each experiment.

\section{Statistical Analyses}

Statistical analyses were conducted on the plot means using a mixed model ANOVA (Proc Mixed, SAS 9.4; SAS Institute, Cary, NC, USA) with genotype, time of day, and DOY considered fixed effects and block and block by genotype effects considered random. SLW, chl content, chl $a / b, A^{\prime}$, mean daily $A_{\text {leaf }}$, mean daily $g_{s}$, mean daily iWUE, mean daily $T_{\text {leaf }}$,

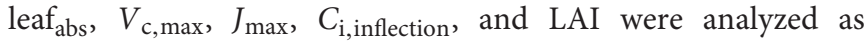
repeated measures with DOY as the repeated factor. Least squared means are reported and shown in figures with the associated standard errors. $\varepsilon_{\mathrm{c}}$ regressions and comparisons were performed on pooled plot data points (Proc Reg, SAS 9.4; SAS Institute, Cary, NC, USA). To reduce the probability of type II errors, an $\alpha$ of 0.1 was used to determine significance.

\section{RESULTS}

\section{Weather Conditions Differed Greatly between 2012 and 2013 but Still Resulted in Drought Conditions in Both Seasons}

Planting occurred 3 weeks later in 2013 as compared to 2012 (Table 1), but mean daily temperatures were similar across both growing seasons (Table 1 and Figures 1A,B). Overall precipitation during 2012 was almost double that of 2013 (Table 1), but annual cumulative precipitation was less than half as much at the start of the 2012 growing season as compared to the 2013 season (Figures 1C,D). Low precipitation amounts prior to planting in 2012 and the fact that most of the 2012 precipitation fell late in the season led to a significant drought from early to mid-season in 2012 (Figure 1C), which was prior to developmental stage R5 (pod filling; data not shown). A moderate drought also occurred late in the 2013 growing season (Figure 1D), the beginning of which corresponded to developmental stage R3 (pod initiation; data not shown). Total 


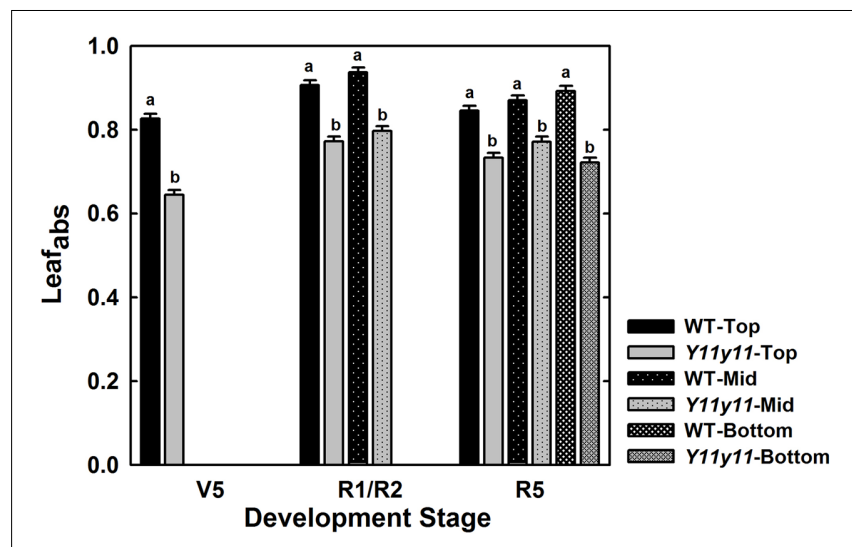

FIGURE 3 | Leaf absorbance as a function of canopy position across the 2013 season. The fraction of absorbed photosynthetically active radiation (PAR) is indicated for WT (black) and Y11y11 (gray) at the top (solid), middle (dotted), and bottom (grid) of the canopy throughout the 2013 season. Error bars represent the standard errors $(n=3)$. Letters indicate significant differences within developmental stage $(\alpha=0.1)$ when present.
$S_{\mathrm{t}}$ (from planting to harvest) was almost 30\% lower during 2013 as compared to 2012 (Figures 1E,F and Table 1) and was slightly lower in the narrow row spacing due to planting 1 day after the wide row spacing (Table 1). Lower $S_{t}$ in 2013 was only partially attributed to a later planting date in 2013 compared to 2012 (Table 1). Total monthly $S_{\mathrm{t}}$ was also greater during the main growing months of 2012. Total monthly $S_{\mathrm{t}}$ was $36 \%$ greater in June, $28 \%$ greater in July, and $8 \%$ greater in August of 2012 compared to the corresponding months in 2013.

\section{SLW and Pigment Concentrations Were Significantly Altered in the Mutants Compared to WT, but Reductions in Leaf $_{\text {abs }}$ Were Less Pronounced}

Specific leaf weight was significantly reduced in the chl mutants in both growing seasons (Supporting Information Table S1). y9y9 SLW was significantly lower than WT SLW on all days but one (DOY 218) during the 2012 season, whereas Y11y11 SLW was significantly reduced on all days but DOY 206 and 218 (Figure 2A). In 2013, Y11y11 SLW was significantly reduced compared to WT on all days except DOY 218 (Figure 2B).

The mutations in Y11y11 and y9y9 caused clear reductions in chl content while increasing the $\mathrm{chl} a / b$ ratios and decreasing total carotenoids. Chl content was significantly affected by the genotype by DOY interaction in both years (Supporting Information Table S1). Mean chl content was significantly reduced by approximately $45-60 \%$ in $Y 11 y 11$ and $y 9 y 9$ across 2012 (Table 2 and Figure 2C). Throughout 2013, Y11y11 chl content was reduced on average by 57\% (Table 2 and Figure 2D). However, mutant chl content was lowest early in both seasons and increased with development (Figures 2C,D). Chl $a / b$ ratios were significantly affected by genotype by DOY interactions in 2012, but only main effects were significant in 2013 (Supporting
Information Table S1). In both seasons the mutant chl $a / b$ ratios were generally greater than WT ratios (Table 2 and Figures 2E,F), but the differences decreased as the 2012 season progressed (Figure 2E), whereas the chl $a / b$ ratios were consistent in both Y11y11 and WT throughout the 2013 growing season (Figure 2F). Total carotenoid content was significantly reduced by $>30 \%$ in $Y 11 y 11$ and $>40 \%$ in $y 9 y 9$ compared to WT (Table 2 and Supporting Information Table S1).

Although Y11y11 chl content was reduced by approximately

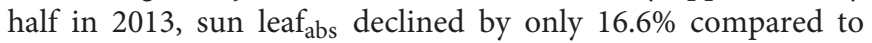
WT (Figure 3 and Table 2). Leaf $f_{\text {abs }}$ was lowest for both WT and Y11y11 during V5, at which time Y11y11 leaf abs was only $78 \%$ of

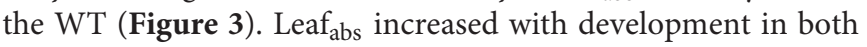

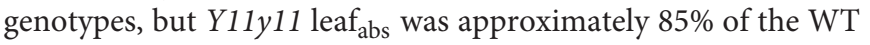
during reproductive stages (Figure 3). Leaf ${ }_{\text {abs }}$ also increased with depth in the canopy except for the lowest layer of the Y11y11 canopy during R5 (Figure 3).

\section{Diurnal Measurements Indicated Transiently Greater $\boldsymbol{A}^{\prime}$ in Mutant Sun Leaves}

Sun leaf $A^{\prime}$ was significantly affected by genotype by DOY interactions in both years (Supporting Information Table S1). Y11y11 $A^{\prime}$ was significantly greater than WT $A^{\prime}$ on 3 days during the 2012 growing season (DOY 191, 206, 248; Figure 4A). y9y9 $A^{\prime}$ was significantly lower than the control on the 1st day of measurements in 2012 but became significantly greater on DOY 191, 206, 218, and 248 (Figure 4A). When averaged over all measurement days from the 2012 growing season, Y11y11 $A^{\prime}$ was $8.6 \%$ greater than WT $A^{\prime}$, but $y 9 y 9 A^{\prime}$ was reduced by $3.6 \%$ (Table 2), mainly due to extremely low $A^{\prime}$ on DOY 178 (Figure 4A). In 2013, Y11y11 $A^{\prime}$ was significantly lower than the control on DOY 193 and significantly greater on DOY 246 (Figure 4B), and there was no significant difference between the mean season $A^{\prime}$ (Table 2).

Shade leaf $A^{\prime}$ was similar among all genotypes when measured in 2012 (Table 2 and Supporting Information Table S1). Although Y11y11 $A_{\text {leaf }}$ was significantly greater than the other two genotypes at the 1200 time point and $y 9 y 9 A_{\text {leaf }}$ was significantly greater than WT and Y11y11 at the 1600 time point (Supporting Information Figure S3A), these increases were not large enough to significantly affect $A^{\prime}$ (Table 2). Incident PPFD within the leaf chamber was based on light measurements within each canopy before each set of gas exchange measurements and was higher for the mutants as compared to the WT (Supporting Information Figure S3B). The reduced chl content of the Y11y11 mutant, however, resulted in a similar amount of absorbed PPFD as compared to WT (Supporting Information Figure S3C).

\section{$A_{\text {leaf }}$ and $g_{\mathrm{s}}$ were Greater in Mutant Sun Leaves whereas iWUE Was Reduced Despite Lower $\boldsymbol{T}_{\text {leaf }}$}

Diurnal measurements were used to calculate the daily means of $A_{\text {leaf }}, g_{s}$, iWUE, and $T_{\text {leaf }}$ in sun leaves. Mean daily $A_{\text {leaf }}$ was significantly affected by genotype by DOY interactions in 2012, but only DOY was significant in 2013 (Supporting Information 

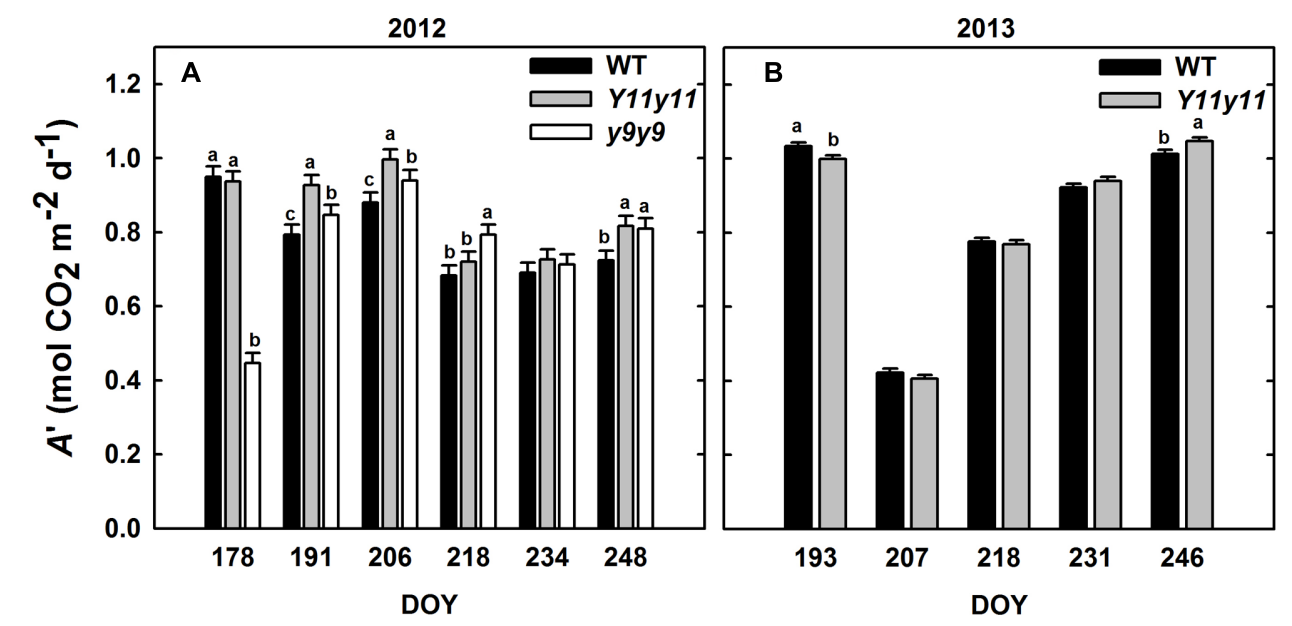

FIGURE 4 | Daily integrals of photosynthesis $\left(\boldsymbol{A}^{\prime}\right)$ from two growing seasons. Diurnal gas exchange measurements were used to calculate $A^{\prime}$ in 2012 (A) and 2013 (B) for WT (black), Y11y11 (gray), and y9y9 (white) soybean. Error bars represent the standard errors $(n=3)$. Letters indicate significant differences within DOY $(\alpha=0.1)$ when present.

Table S1). The within-day relationships between WT and mutant $A_{\text {leaf }}$ were similar to those listed above for $A^{\prime}$. In 2012, y9y9 $A_{\text {leaf }}$ was significantly lower than WT only on DOY 178 but was significantly greater than WT on DOY 191, 206, 218, and 248 (Figure 5A). $A_{\text {leaf }}$ in $Y 11 y 11$ was significantly greater than WT on DOY 191, 206, and 248 in 2012 (Figure 5A), leading to a significant $8.5 \%$ increase in mean season $A_{\text {leaf }}$ in Y11y11 (Table 2). In 2013, Y11y11 $A_{\text {leaf }}$ was significantly lower than WT on DOY 193 but greater on DOY 246 (Figure 5B), resulting in no significant changes in season-long $A_{\text {leaf }}$ (Table 2). $g_{\text {s }}$ and iWUE were also significantly affected by the interaction effect (Supporting Information Table S1), but contrary to expectations, $g_{\mathrm{s}}$ was approximately $20-30 \%$ greater in the mutants across both seasons (Table 2 and Figures 5C,D), resulting in lower mutant iWUE across both seasons (Table 2 and Figures 5E,F). The diurnal iWUE data were supported by $\delta^{13} \mathrm{C}$ signature, in which the mean $Y 11 y 11$ signature across leaf position $(-28.8 \%$ ) was significantly lower than the mean WT signature $(-27.9 \%$; $p<0.0001$; Supporting Information Figure S4). This indicated greater ${ }^{13} \mathrm{C}$ discrimination in Y11y11 and therefore higher $g_{\mathrm{s}}$ over the integral of leaf development across three layers of the canopy (Supporting Information Figure S4). $T_{\text {leaf }}$ was significantly affected by the interaction between genotype and DOY in 2012 $(p<0.01)$ and the separate effects of genotype $(p<0.0001)$ and DOY $(p<0.0001)$ in 2013 (Supporting Information Table S1). As predicted, WT $T_{\text {leaf }}$ was generally greater than mutant $T_{\text {leaf }}$ in both seasons (Table 2 and Figures 5G,H), which correlated with

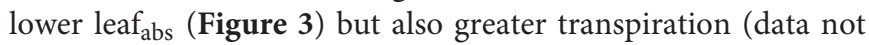
shown) in the mutants, which correlated with the higher $g_{\mathrm{s}}$.

\section{Y11y11 Sun Leaves Demonstrated Greater Light Use Efficiency Compared to WT Early in the Growing Season}

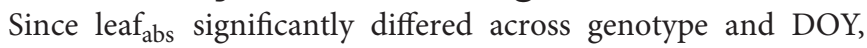
$A / Q$ measurements were based on absorbed PPFD instead of incident PPFD. In both seasons, Y11y11 sun leaves reached greater rates of $A_{\text {leaf }}$ with fewer absorbed photons at high light levels during the V5 stage, demonstrating greater light use efficiency (Figure 6). Genotype main effects on sun leaf $A_{\text {sat }}$ were significant in both years (Supporting Information Table S1). Y11y11 sun leaves had a $43 \%$ higher $A_{\text {sat }}$ early in 2012, whereas y9y9 $A_{\text {sat }}$ was lower by $14 \%$ compared to WT (Tables 2, 3). In 2013, significant differences in $A_{\text {sat }}$ occurred during R1/R2 (Table 3) but did not result in season-long differences (Table 2). The relationship between $A_{\text {sat }}$ and chl shows a steep increase at chl contents less than $100 \mu \mathrm{mol}$ $\mathrm{m}^{-2}$ and a more graduate decline with chl contents greater than $200 \mu \mathrm{mol} \mathrm{m} \mathrm{m}^{-2}$ (Supporting Information Figure S5A). $\phi \mathrm{CO}_{2}$ was greater in Y11y11 sun leaves compared to WT during the V5 stage of 2013, but season averages did not differ between the two genotypes in either year (Tables 2, 3 and Supporting Information Table S1). On the other hand, y9y9 sun leaf $\phi \mathrm{CO}_{2}$ was significantly impaired early in 2012 when chl content was severely reduced (Tables 2, 3). Genotype effects were not significant within shade leaf $A_{\text {sat }}$ or $\phi \mathrm{CO}_{2}$ analyses in 2013 (Tables 2, 3 and Supporting Information Table S1).

\section{Chl Fluorescence Parameters Varied with Chl Content and Developmental Stage}

Sun leaf $\phi P S I I$ was significantly lower in y9y9 in 2012 and Y11y11 during R5 of 2013 (Figure 6). In 2012, the decrease in y9y9 $\phi P S I I$ was accompanied by substantially lower NPQ compared to the other two genotypes in mid to high light conditions (Figure 6). However, NPQ was similar between WT and Y11y11 early in both seasons and greater in Y11y11 during R5 in 2013 at mid to high light levels (Figure 6). Y11y11 ETR was greater than WT ETR at high light levels in 2012, but there were no significant differences in 2013 (Figure 6). 

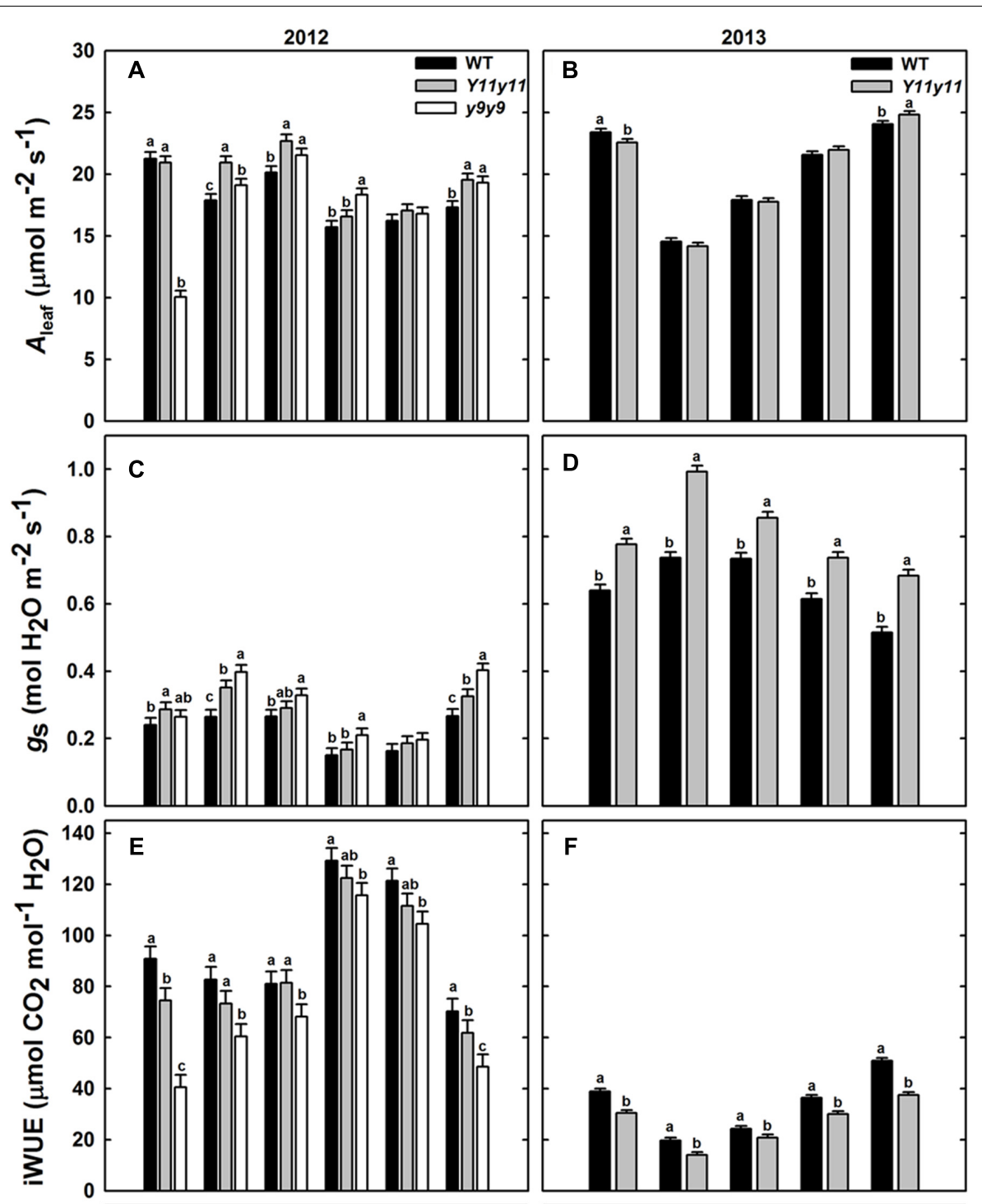

$F$
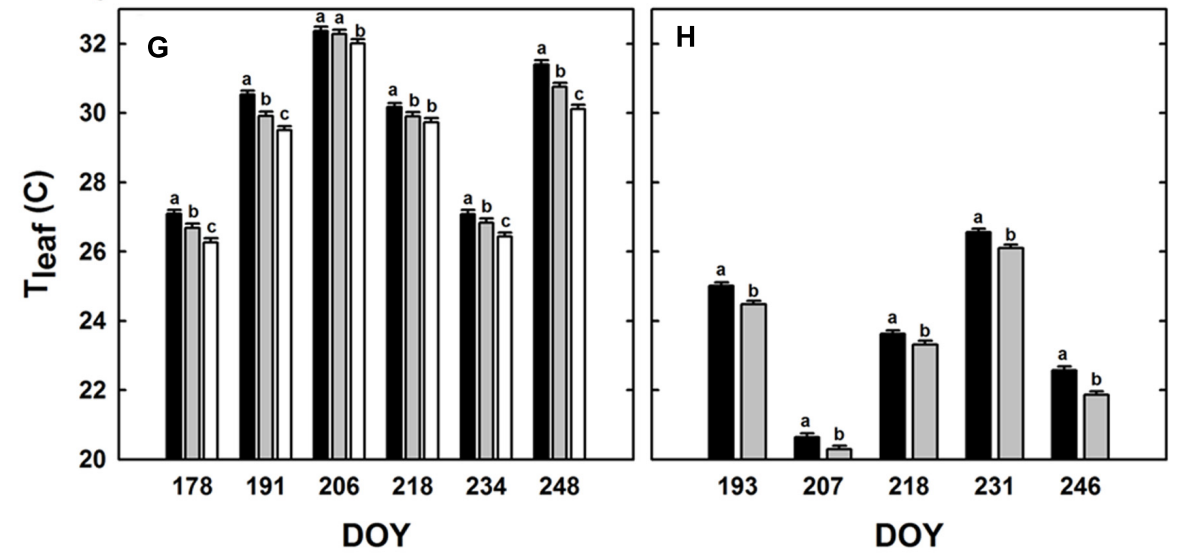

FIGURE 5 | Diurnal measurements in sun leaves from two growing seasons. Bars represent daily means of photosynthesis ( $A_{\text {leaf }}$; A,B), stomatal conductance $\left(g_{s} ; \mathbf{C , D}\right)$, intrinsic water use efficiency (iWUE; E,F), and leaf temperature ( $T_{\text {leaf }} ; \mathbf{G}, \mathbf{H}$ ) across the 2012 (A,C,E,G) and 2013 (B,D,F,H) growing seasons for WT dark green soybean (black) and two chl-deficient soybean mutants $(Y 11 y 11=$ gray; $y 9 y 9=$ white). Error bars represent the standard errors $(n=3)$. Letters indicate significant differences within DOY $(\alpha=0.1)$ when present. 


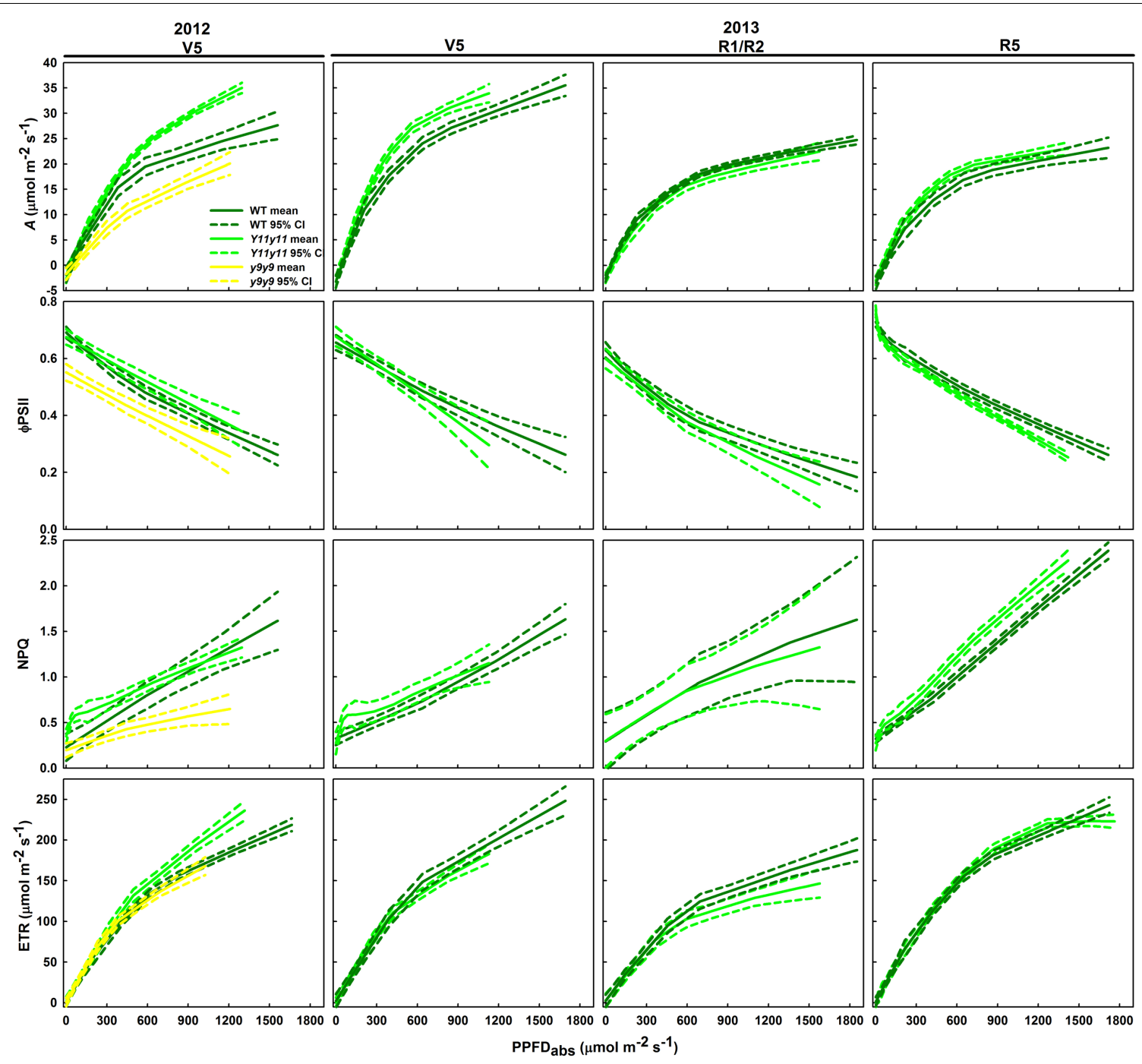

FIGURE 6 | Light response curves from various developmental stages across two growing seasons in sun leaves. $A_{\text {leaf }}, \phi P S / l, N P Q$, and $E T R$ as a function of absorbed PPFD are shown in sun leaves during V5 of 2012 and during V5, R1/R2, and R5 of 2013. Means (solid line) and $90 \%$ confidence intervals (dashed lines) are indicated for each genotype $(n=3)$.

\section{Chl Reductions Had Little Effect on Biochemical Photosynthetic Capacity}

Enhanced biochemical photosynthetic capacity, as measured by $A / C_{\mathrm{i}}$ curves, were transient in these specific mutants. Within sun leaf analyses, Y11y11 had higher $V_{c, \max }$ compared to WT on DOY 190 in 2012 (Figure 7A). Conversely, $V_{c, \max }$ was reduced in $y 9 y 9$ on DOY 175 in 2012 (Figure 7A). This corresponded to a $>85 \%$ reduction in $y 9 y 9 \mathrm{chl}$ content (Figure 2C) and a significant decrease in $A_{\text {leaf }}$ (Figure 5A). There were no significant differences between WT and Y11y11 $V_{\mathrm{c}, \max }$ in 2013 (Figure 7B). $J_{\max }$ was also slightly lower in $y 9 y 9$ sun leaves on DOY 175 (Figure 7D). However, $J_{\max }$ was greatest in Y11y11 sun leaves on DOY 190 in 2012 (Figure 7D) and in the R1/R2 developmental stage in 2013 (Figure 7E). Both $V_{c, \max }$ and $J_{\max }$ showed similar relationships with chl content that declined steeply at chl contents less than $100 \mu \mathrm{mol} \mathrm{m}^{-2}$ while declining more gradually at chl contents greater than approximately $200 \mu \mathrm{mol} \mathrm{m}^{-2}$ (Supporting Information Figures S5B,C). Sun leaf $C_{\mathrm{i} \text {,inflection }}$ differed in $y 9 y 9$ compared to WT and Y11y11 both early and late in the 2012 season (Figure 7G) with no significant effects occurring between WT and Y11y11 in 2013 (Supporting Information Table S1 and Figure 7H). In 2013, WT and Y11y11 shade leaf parameters did not differ in R1/R2, but $V_{c, \text { max }}$ and $J_{\max }$ were significantly greater in WT compared to Y11y11 in R5 (Figures 7C,F,I).

\section{$R_{\mathrm{d}}$ Was Significantly Lower in Y11y11 than WT during 2013 Reproductive Stages}

A significant genotype effect $(p<0.01)$ on $R_{\mathrm{d}}$ was evident in sun leaves during 2013 (Supporting Information Table S1). Y11y11 $R_{\mathrm{d}}$ in sun leaves was $13 \%$ lower than WT across the experiment 
TABLE 3 | Parameters from photosynthetic light response $(A / Q)$ curves in two growing seasons.

\begin{tabular}{|c|c|c|c|c|c|c|c|c|}
\hline \multirow[b]{3}{*}{ Parameter } & \multirow[b]{3}{*}{ Stage } & \multicolumn{3}{|c|}{2012} & \multicolumn{4}{|c|}{2013} \\
\hline & & \multicolumn{3}{|c|}{ Sun } & \multicolumn{2}{|c|}{ Sun } & \multicolumn{2}{|c|}{ Shade } \\
\hline & & WT & $Y 11 y 11$ & $y 9 y 9$ & WT & $Y 11 y 11$ & WT & Y11y11 \\
\hline \multirow[t]{4}{*}{$A_{\text {sat }}$} & V5 & $33.2 \mathrm{~b}$ & $47.4 a$ & $28.6 b$ & $42.1 \mathrm{a}$ & $41.0 \mathrm{a}$ & - & - \\
\hline & $\mathrm{R} 1 / 2$ & - & - & - & $31.6 a$ & $28.1 b$ & $27.2 \mathrm{a}$ & $19.1 \mathrm{a}$ \\
\hline & $\mathrm{R} 5$ & - & - & - & $29.9 a$ & $27.6 a$ & $34.5 a$ & $35.4 \mathrm{a}$ \\
\hline & MSE & & 4.3 & & \multicolumn{2}{|c|}{1.3} & \multicolumn{2}{|c|}{4.9} \\
\hline \multirow[t]{4}{*}{$\phi \mathrm{CO}_{2}$} & V5 & $0.068 a$ & $0.061 a$ & 0.036b & $0.067 b$ & $0.081 a$ & - & - \\
\hline & $\mathrm{R} 1 / 2$ & - & - & - & $0.047 a$ & $0.043 a$ & $0.063 a$ & $0.056 a$ \\
\hline & R5 & - & - & - & $0.048 a$ & $0.058 a$ & $0.057 a$ & $0.064 a$ \\
\hline & MSE & & 0.00004 & & \multicolumn{2}{|c|}{0.003} & \multicolumn{2}{|c|}{0.005} \\
\hline
\end{tabular}

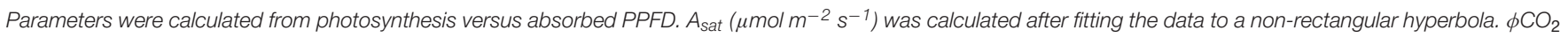

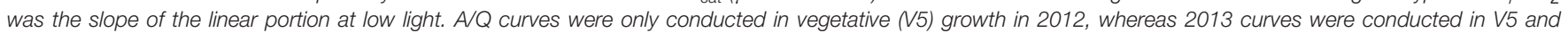

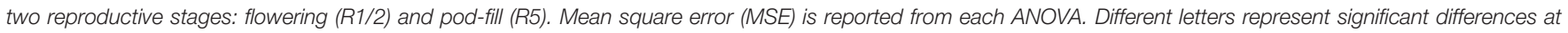
$\alpha=0.1$.

(Table 2 and Supporting Information Figure S6A). An apparent reduction of $\sim 12 \%$ was seen in Y11y11 shade leaves (Table 2 and Supporting Information Figure S6B), but shade leaf genotype effects on $R_{\mathrm{d}}$ were not significant (Supporting Information Table S1).

\section{Mutant Canopies Absorbed Less Light Early in the Season Despite Similar LAI}

Canopy LAI was only significantly affected by chl reductions in 2012 ( $p<0.05)$. In 2012, WT and y9y9 reached peak LAI on DOY 208, on which day WT LAI was significantly greater than mutant LAI by 25-30\% (Figure 8A). Y11y11 did not reach peak LAI until DOY 220 (Figure 8A). y9y9 LAI was also significantly lower than WT by $\sim 30 \%$ on DOY 220 and 236 (Figure 8A). There were no significant within-day differences between WT and Y11y11 LAI in 2013 wide row widths (Figure 8B). Within-day differences between WT and Y11y11 LAI in 2013 were only significant in the narrow row widths on DOY 221 (Figure 8C).

Light interception measurements in 2012 began when both the WT and Y11y11 canopies had already reached interception fractions of $\sim 0.8$ (Figure 8D). The $y 9 y 9$ canopy did not reach this fraction of light interception until approximately 2 weeks later but intercepted slightly more light at the end of the season (Figure 8D). Light interception measurements began relatively earlier in canopy development in 2013 and showed a slight lag in light interception by the Y11y11 canopy as compared to WT in wide row spacing (Figure 8E) and a substantial lag in the narrow row spacing (Figure $\mathbf{8 F}$ ).

\section{$A_{\text {can }}$ Was Similar in WT and Y11y11 Plots during the 2013 Season}

$A_{\text {can }}$ was calculated for each genotype based on $\mathrm{CO}_{2}$ drawdown rates that accounted for soil respiration and leaf area within an enclosed chamber. The WT and Y11y11 canopies had similar $A_{\text {can }}$ on a leaf area basis ( $p=0.41$; Figure 9). A significant DOY effect $(p<0.0001)$ most likely occurred because average photosynthetic rates on a leaf area basis decreased drastically after canopy closure (Figures $\mathbf{8 B}, \mathbf{E}$ ) as the area of shaded leaves increased in proportion to fully sunlit leaves in both genotypes (data not shown).

\section{Effects of Chl Reductions Were More Pronounced on $\varepsilon_{\mathrm{i}}$ Compared to $\varepsilon_{\mathrm{c}}$ or $\varepsilon_{\mathrm{p}}$}

$\varepsilon_{\mathrm{i}}, \varepsilon_{\mathrm{c}}$, and $\varepsilon_{\mathrm{p}}$ were calculated for WT, Y11y11, and $y 9 y 9$ in 2012 and WT and Y11y11 in 2013, which also incorporated a row spacing treatment. In 2012, a significant decrease occurred in $y 9 y 9 \varepsilon_{i}$ compared to WT and $Y 11 y 11$, and $\varepsilon_{\mathrm{i}}$ was significantly lower in narrow rows of Y11y11 compared to WT in 2013 (Tables 4,5$)$. In calculating $\varepsilon_{\mathcal{c}}$, biomass was corrected for leaf, stem, and pod energy content. Pod energy, measured in 2013 only, differed between WT and Y11y11 during late R5 (Supporting Information Table S2) and was $1 \mathrm{MJ} \mathrm{kg}^{-1}$ lower during R8 than the reported value from Amthor et al. (1994; Supporting Information Table S2). Although differences in $\varepsilon_{\mathrm{c}}$ were not resolvable at $\alpha=0.1$ (Table 4), the percent reduction between WT and Y11y11 $\varepsilon_{\mathrm{c}}$ was less in the wide row spacing experiment of 2013 (3\%) compared to 2012 (10\%), and Y11y11 $\varepsilon_{\mathrm{c}}$ was almost $10 \%$ greater than WT $\varepsilon_{\mathrm{c}}$ in the narrow row spacing of 2013 (Table 5). $\varepsilon_{\mathrm{p}}$ was not significantly affected by genotype in either year or row spacing treatment (Tables 4, 5).

\section{Reducing Chl Content Did Not Improve Yield in the Mutants}

Overall yields were generally lower in 2012 compared to 2013 (Table 5), even though $S_{\mathrm{t}}$ was $30 \%$ greater in 2012 (Table 1). The lower yield is most likely due to a severe drought that occurred early in the 2012 growing season (Figure 1C). WT yield was significantly greater than $y 9 y 9$ yield in 2012 and Y11y11 yield in 2013 wide row spacing (Table 4). Measured yields were not significantly different in the narrow row spacing of 2013 (Table 5). In addition, seed mass per 100 seeds was significantly reduced in $y 9 y 9$ during 2012 and Y11y11 during 2013 (Table 5). 

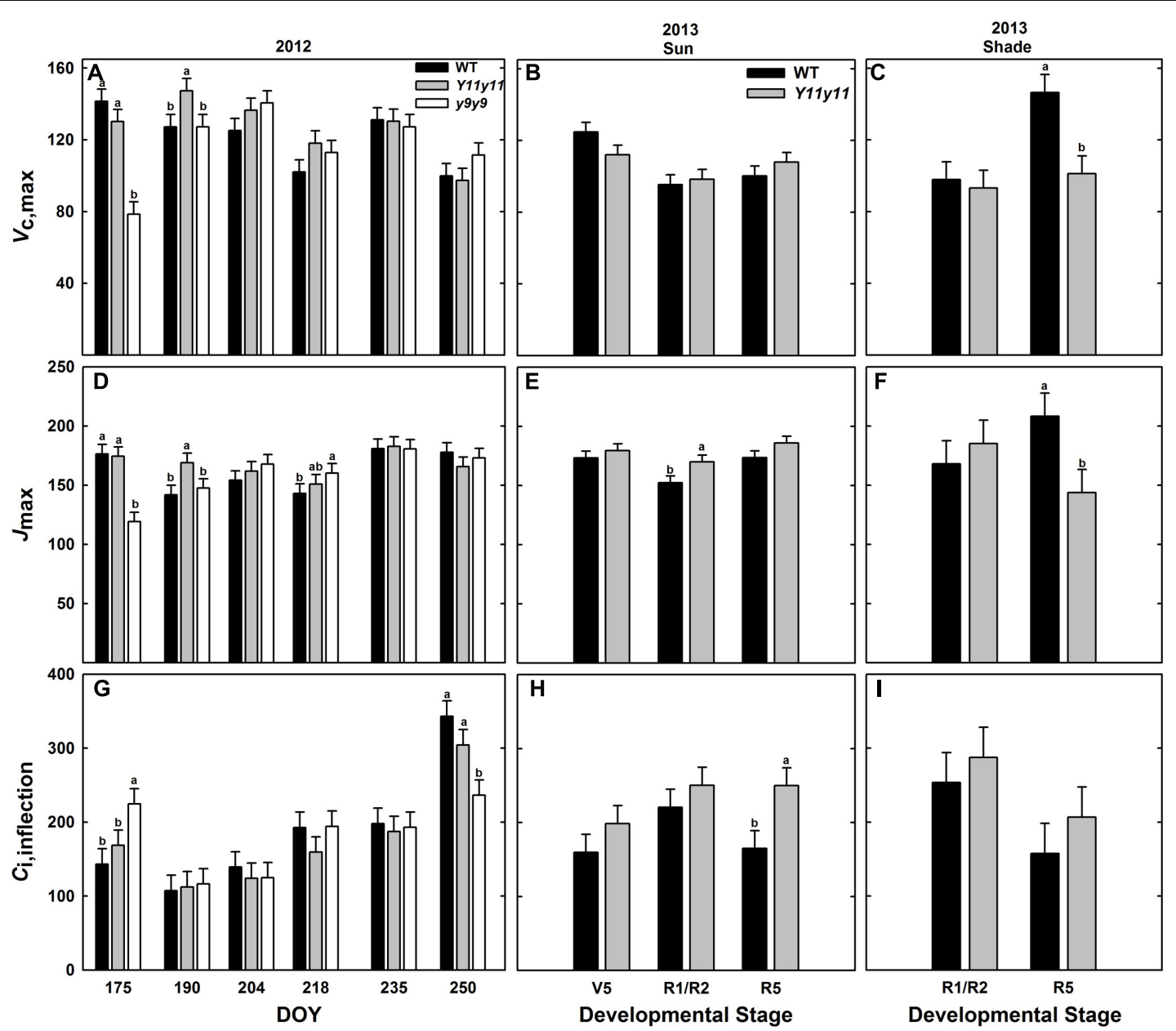

FIGURE 7 | Parameters from photosynthetic $\mathbf{C O}_{\mathbf{2}}$ response $\left(\mathbf{A} / \boldsymbol{C}_{\mathrm{i}}\right)$ curves across two growing seasons. $V_{\mathrm{c}, \text { max }}(\mathbf{A}-\mathbf{C})$, $J_{\text {max }}(\mathbf{D}-\mathbf{F})$, and $C_{\mathrm{i}, \text { inflection }}(\mathbf{G}-\mathbf{I})$ from 2012 sun leaves (A,D,G), 2013 sun leaves (B,E,H), and 2013 shade leaves (C,F,I) are reported for WT (black), Y11y11 (gray), and y9y9 (white) soybean. Error bars represent standard errors $(n=3)$. Letters indicate significant differences within DOY or developmental stage $(\alpha=0.1)$ when present.

\section{DISCUSSION}

Reducing chl content in soybean was hypothesized to lead to an improved distribution of light in the canopy, resulting in benefits to leaf and canopy photosynthesis and therefore yield (Zhu et al., 2010; Ort et al., 2011; Drewry et al., 2014). This hypothesis was tested on two chl-deficient mutants that reportedly performed well in optimal field conditions in a previous study (Pettigrew et al., 1989). As the 1st year of the field study revealed severe limitations in the $y 9 y 9$ mutant, the 2nd year focused on comparison of the Y11y11 mutant to the WT and by adding a narrow row spacing treatment that modeling predicted would advantage the light-green phenotype due to earlier canopy closure. Despite transient benefits to mutant leaflevel photosynthesis, no increases in canopy-level processes were evident during either growing season, both of which experienced drought conditions. While the results of this study confirmed neither our hypothesis nor the earlier published work in which the Y11y11 mutant significantly outyielded the parental Clark cultivar, they do indicate that soybean, and likely many other crop plants, significantly overinvest in chl since a $>50 \%$ chl reduction had little negative impact on biomass accumulation or yield. In addition, the small negative effects reduced chl did have on yield in our study were likely due to pleiotropic effects of the mutation. This outcome suggests that more sophisticated approaches for chl reduction, such as developmentally timed transgenic technology, may promote an opportunity to reinvest nitrogen and energy resources saved in chl reduction into increasing the biochemical photosynthetic capacity, leading to increased yield.

Although the Y11y11 mutant demonstrated the potential to surpass WT in light use efficiency and $A_{\text {sat }}$, the improvements were transient. The increases in light use efficiency corresponded with a narrow range of chl reductions (Table 3 and Figures 2C,D, 6), which may support the hypothesis that an optimal chl content exists and is lower than current levels (Ort et al., 2011). Benefits to $A_{\text {leaf }}$ were seen only when chl content in Y11y11 was reduced to $30-40 \%$ of WT (Figures 2C,D), which corresponded to a $22 \%$ reduction in leaf abs (Figure 3) 


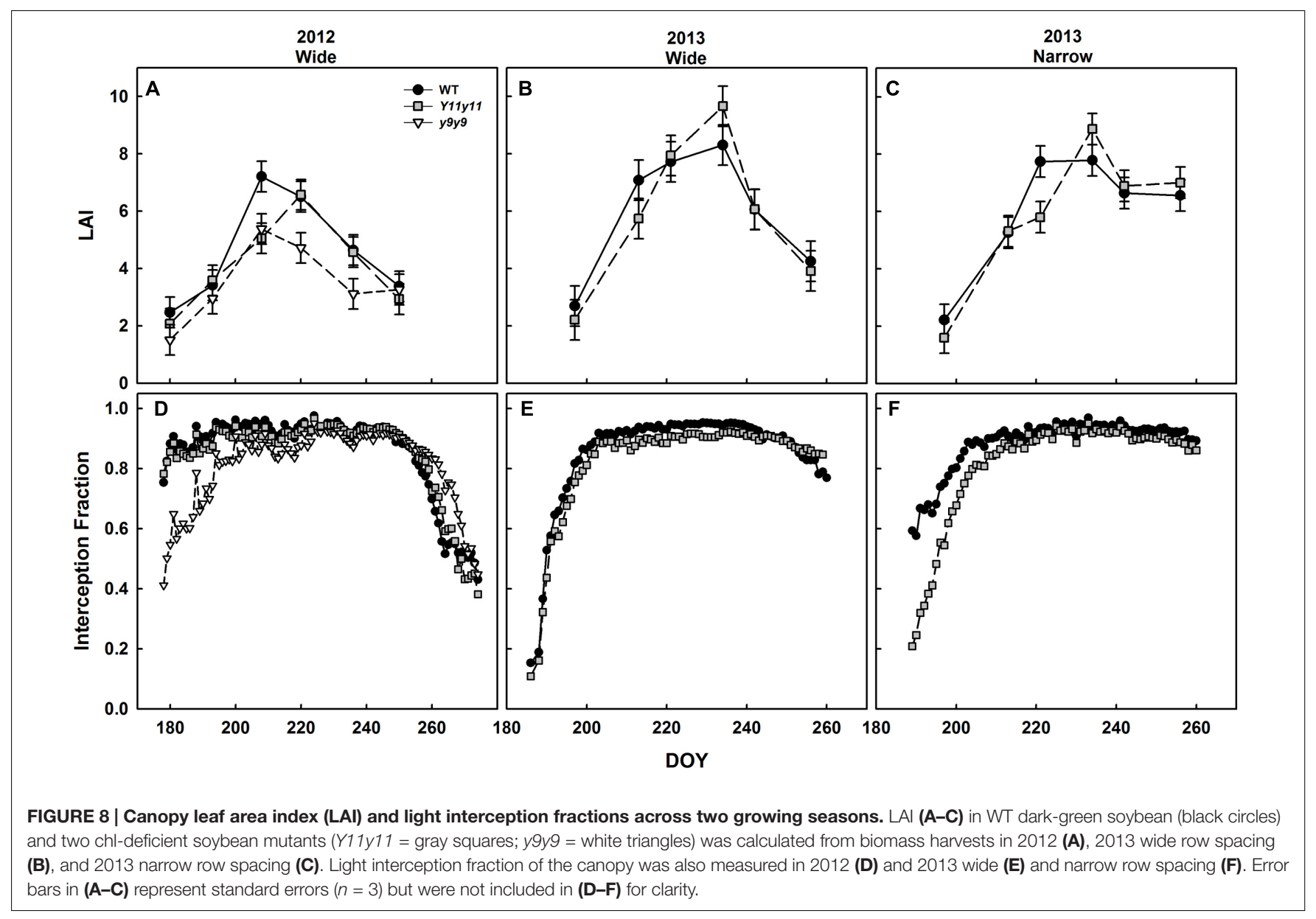

that is less than the reduction predicted by Beer's law (Slattery et al., 2016). As chl content increased in the mutant throughout the growing season (Figures $\mathbf{2 C , D}$ ) and the percent difference between mutant and WT leaf abs decreased (Figure 3), benefits at the leaf level became too small to resolve (Figure 6). In other species, chl contents correlated with increased $A_{\text {leaf }}$ ranged from $30 \%$ in tobacco (Edwards et al., 1993) to $60 \%$ in maize (Edwards et al., 1993) and cowpea (Habash et al., 1994) as compared to the dark-green WT, suggesting that optimal chl content may be species specific.

Improved leaf light use efficiency is the anticipated result of improved light distribution within the low chl leaf. In dark-green leaves, the majority of light absorption occurs in the uppermost adaxial chloroplasts, causing light limitation in lower chloroplasts (Vogelmann and Evans, 2002; Evans and Vogelmann, 2003; Slattery et al., 2016). This has been shown to create a withinleaf gradient in photosynthesis (Evans and Vogelmann, 2003) as well as photoinhibition (Oguchi et al., 2011) that decreases with depth in the leaf and limits overall photosynthetic efficiency. Light sheet microscopy analyses revealed more gradual PPFD attenuation in light-green soybean leaves compared to darkgreen leaves. This resulted in significantly more red and blue light reaching the spongy mesophyll chloroplasts of the lightgreen leaves, which correlated with greater photosynthetic light use efficiency (Slattery et al., 2016). Thus, if chloroplasts within the leaf mimic leaves within a canopy, then decreasing chl content may have ameliorated the large disparity of light availability in the lower leaf to increase photosynthetic light use efficiency.

However, other attributes of the chl mutants may have also played roles in altering photosynthetic performance. SLW was reduced in both mutants (Figures $\mathbf{2 A}, \mathbf{B}$ ). Changes in SLW are due to changes in either leaf thickness or leaf density, both of which can affect photosynthesis (Niinemets, 1999). Although leaf thickness was not directly measured in this study, leaf thickness did not change in a previous study on the same soybean genotypes, even when SLW was significantly different (Slattery et al., 2016). Therefore, changes in SLW were almost certainly due to reduced leaf density in the chl mutants, which can increase the proportion of intercellular space and thus improve $\mathrm{CO}_{2}$ diffusion throughout the leaf (Niinemets, 1999). In addition, chl deficiency in these mutants was accompanied by increased $g_{s}$, which would increase carbon supply to the inner leaf and further confound deciphering the chl reduction impact on $A_{\text {leaf }}$. A similar increase in $g_{s}$ was seen in rice chl mutants that exhibited greater rates of $A_{\text {leaf }}$ in non-limiting environmental conditions ( $\mathrm{Gu}$ et al., 2017). Those authors hypothesized that the increase in $g_{s}$ may have been due to changes in vein 


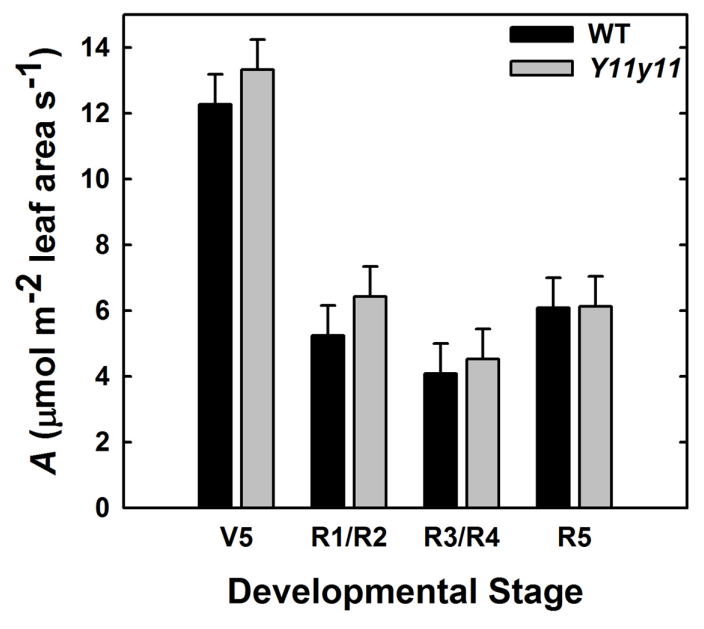

FIGURE 9 | Photosynthetic rate $(A)$ per unit leaf area of the entire canopy across several developmental stages during the $\mathbf{2 0 1 3}$ growing season. $A_{\text {can }}$ in WT (black) and $Y 11$ y11 (gray) was measured using a chamber and reported after correcting for soil respiration and leaf area inside the chamber. Error bars represent the standard and errors $(n=3)$. There were no significant differences between values within developmental stages $(\alpha=0.1)$.

structure in the rice mutants (Gu et al., 2017). More analyses are needed to separate the effects of reduced chl, increased $g_{s}$, and altered leaf anatomy on $A_{\text {leaf }}$ improvements or the lack thereof.

A decline in photosynthetic efficiency and capacity in y9y9 was correlated with severe reductions in chl. Despite greater $g_{s}$ and lower SLW, which was evident in Y11y11 as well, the y9y9 mutant displayed reduced $A_{\text {sat }}$ and light use efficiency compared to the WT (Figures 4A, 5A, 6, 7A and Table 3) when chl was reduced by more than $85 \%$ compared to the WT (Figure 2C). Similar responses to severe reductions in chl content $(>80 \%)$ seen in $y 9 y 9$ have been reported in $Y 11 y 11$ when grown in controlled environment chambers at lower than field light levels (Xu et al., 1993; Slattery et al., 2016). These two mutants are characterized by higher chl $a / b$ ratios due to greatly reduced PSII-associated light harvesting complexes (LHCII) and to some extent PSI-associated light harvesting complexes (LHCI; Ghirardi and Melis, 1988). Theoretically, severe deficiencies in LHCII could have negative effects at the leaf level, including greater levels of photoinhibition (Leverenz et al., 1992; Xu et al., 1993), reduced photoprotective capacity (Ort, 2001), and lowered connectivity among PSII centers and therefore lower quantum yield at low light (Allen and Forsberg, 2001). In this study, extreme reductions in chl coupled with large reductions in carotenoids ( $>40 \%$; Table 2 ) were correlated with impaired photoprotective mechanisms such as NPQ (Figure 6). $\phi \mathrm{CO}_{2}$ was also significantly reduced in $y 9 y 9$ (Tables 2,3 ). Thus, these data suggest improving leaf photosynthetic efficiency through lowering chl $a$ and chl $b$ concentrations proportionally, but not to an extent that impairs photosynthetic and photoprotective capacity.
Despite transient leaf-level improvements in photosynthesis and photosynthetic efficiency, chl reductions only significantly affected the canopy parameter of $\varepsilon_{\mathrm{i}}$. Although no improvements in $A_{\text {can }}$ or $\varepsilon_{\mathrm{c}}$ were evident in the chl-deficient soybean, the fact that there was also no decline in these parameters with a $>50 \%$ reduction in chl suggests that soybean significantly overinvest in chl. This is consistent with a recent study that showed soybean also overinvest in LAI to the detriment of canopy productivity (Srinivasan et al., 2016). However, less pigment led to significant depressions in $\varepsilon_{\mathrm{i}}$ in $y 9 y 9$ in 2012 and Y11y11 in 2013 narrow row widths (Tables 4,5), mostly due to reduced light interception by the mutants early in the season, even when LAI was similar (Figure 8). The mutant chl content in this study was the lowest early in the season (Figures 2C,D), which would be expected to both increase transmission to the soil and increase the proportion of reflectance not reabsorbed by upper canopy leaves during early growth. As LAI increased, chl content also increased in the mutants, which in turn would be expected to limit light penetration to deeper layers in the canopy. An ideal situation for maximizing light absorption early in the season would be normal chl content until the canopy has closed (Melis, 2009). This would suppress weed vigor through increased competitiveness, which is reasoned to be why plants evolved with much higher chl content than is needed to maximize photosynthesis (Donald, 1968). As LAI increases, decreasing chl biosynthesis in new leaves would alleviate oversaturation in times of high light and allow greater transmittance to the lower canopy. However, light reflection and thus loss of canopy absorbance will also increase at the top of the canopy; thus, a more light-use efficient canopy may not necessarily lead to an increase in $A_{\text {can }}$ from chl reductions alone.

Reduced pigmentation was hypothesized to benefit leaf water use along with canopy $\varepsilon_{\mathrm{c}}$, but the greater $g_{\mathrm{s}}$ that accompanied chl reductions in these mutants likely prevented these effects. Increased albedo was associated with lower $T_{\text {leaf }}$ in the mutants as expected (Figures 5G,H), but cooler $T_{\text {leaf }}$ may have been, at least in part, an effect of greater $g_{s}$ and therefore cooling via transpiration in the mutants (Figures 5E,F). Greater $g_{\text {s }}$ was most likely a result of the mutations causing chl deficiency. A recent study identified a mutation in the magnesium chelatase subunit-I gene (CHLI) as the cause of the light-green phenotype of Y11y11 (Campbell et al., 2015). In A. thaliana, both CHLI and CHLH mutants have demonstrated ABA-insensitivity (Tsuzuki et al., 2011; Du et al., 2012) that is independent of chl biosynthesis (Du et al., 2012). Whether the greater $g_{s}$ in $y 9 y 9$ that occurred in this study is also due to ABA-insensitivity is unknown since the mutation has not yet been identified, but greater $g_{\mathrm{s}}$ has been reported in $y 9 y 9$ compared to $\mathrm{WT}$ regardless of water stress (Luquez et al., 1997). The increase in $g_{\mathrm{s}}$ resulted in lower mutant iWUE (Figures 5C,D) and integrated canopy WUE (Supporting Information Figure S4). Lower canopy WUE in the mutants would likely result in greater soil moisture depletion (Hussain et al., 2013) and therefore greater susceptibility to drought, which occurred during both of the growing seasons (Figures 1C,D). Drought stress significantly reduces $\varepsilon_{\mathrm{c}}$ (Slattery et al., 2013), and the greater susceptibility to drought in the mutants may have dampened even small benefits of reduced chl on $\varepsilon_{\mathrm{c}}$ and yield. 
TABLE 4 | ANOVA results of genotype effects on canopy parameters across two different years and row spacing treatment levels in 2013.

\begin{tabular}{|c|c|c|c|c|c|c|}
\hline \multirow[b]{3}{*}{ Parameter } & \multirow{2}{*}{\multicolumn{2}{|c|}{$\begin{array}{c}2012 \\
0.38 \mathrm{~m} \text { row space }\end{array}$}} & \multicolumn{4}{|c|}{2013} \\
\hline & & & \multicolumn{2}{|c|}{$0.38 \mathrm{~m}$ row space } & \multicolumn{2}{|c|}{$0.19 \mathrm{~m}$ row space } \\
\hline & $F$-value & $P$-value & $F$-value & $P$-value & $F$-value & $P$-value \\
\hline$\varepsilon_{i}$ & 8.81 & $<0.05$ & 4.56 & 0.17 & 16.6 & $<0.1$ \\
\hline$\varepsilon_{\mathrm{C}}$ & 0.87 & 0.43 & 0.47 & 0.50 & 0.79 & 0.38 \\
\hline$\varepsilon_{\mathrm{p}}$ & 2.72 & 0.18 & 1.85 & 0.31 & 4.40 & 0.17 \\
\hline Seed yield & 8.77 & $<0.05$ & 38.8 & $<0.05$ & 1.15 & 0.40 \\
\hline Seed mass & 2.78 & 0.18 & 784 & $<0.01$ & 9.41 & $<0.1$ \\
\hline
\end{tabular}

Effects of genotype on interception efficiency $\left(\varepsilon_{i}\right)$, conversion efficiency $\left(\varepsilon_{c}\right)$, partition efficiency $\left(\varepsilon_{p}\right)$, seed yield, and seed mass are indicated.

TABLE 5 | Parameter estimates of canopy level processes related to the Monteith equation (Monteith, 1977) and yield.

\begin{tabular}{|c|c|c|c|c|c|c|c|}
\hline \multirow[b]{3}{*}{ Parameter } & \multicolumn{3}{|c|}{2012} & \multicolumn{4}{|c|}{2013} \\
\hline & \multicolumn{3}{|c|}{$0.38 \mathrm{~m}$ row space } & \multicolumn{2}{|c|}{$0.38 \mathrm{~m}$ row space } & \multicolumn{2}{|c|}{$0.19 \mathrm{~m}$ row space } \\
\hline & WT & Y11y11 & $y 9 y 9$ & WT & Y11y11 & WT & Y11y11 \\
\hline Incident PAR (MJ m²) & 883 & 883 & 883 & 642 & 642 & 642 & 642 \\
\hline$\varepsilon_{i}$ & $\begin{array}{l}0.868 a \\
(0.034)\end{array}$ & $\begin{array}{l}0.860 a \\
(0.034)\end{array}$ & $\begin{array}{l}0.801 b \\
(0.034)\end{array}$ & $\begin{array}{l}0.882 a \\
(0.008)\end{array}$ & $\begin{array}{l}0.857 a \\
(0.008)\end{array}$ & $\begin{array}{l}0.878 a \\
(0.012)\end{array}$ & $\begin{array}{l}0.807 b \\
(0.012)\end{array}$ \\
\hline$\varepsilon_{\mathrm{C}}$ & $\begin{array}{c}0.0226 a \\
(0.002) 12\end{array}$ & $\begin{array}{c}0.0204 a \\
(0.001) 14\end{array}$ & $\begin{array}{c}0.0198 a \\
(0.002) 14\end{array}$ & $\begin{array}{c}0.0272 \mathrm{a} \\
(0.003) 18\end{array}$ & $\begin{array}{c}0.0263 a \\
(0.003) 18\end{array}$ & $\begin{array}{c}0.0319 a \\
(0.002) 18\end{array}$ & $\begin{array}{c}0.0330 a \\
(0.004) 18\end{array}$ \\
\hline$\varepsilon_{\mathrm{p}}$ & $\begin{array}{l}0.476 a \\
(0.017)\end{array}$ & $\begin{array}{l}0.490 a \\
(0.017)\end{array}$ & $\begin{array}{l}0.518 a \\
(0.017)\end{array}$ & $\begin{array}{l}0.416 a \\
(0.021)\end{array}$ & $\begin{array}{l}0.421 a \\
(0.021)\end{array}$ & $\begin{array}{l}0.495 a \\
(0.033)\end{array}$ & $\begin{array}{l}0.542 a \\
(0.033)\end{array}$ \\
\hline Seed yield $\left(\mathrm{g} \mathrm{m}^{-2}\right)$ & $\begin{array}{c}184.4 \mathrm{a} \\
(7.8)\end{array}$ & $\begin{array}{c}157.2 \mathrm{ab} \\
(7.8)\end{array}$ & $\begin{array}{c}136.7 \mathrm{~b} \\
(7.8)\end{array}$ & $\begin{array}{c}324.6 \mathrm{a} \\
(11.5)\end{array}$ & $\begin{array}{c}223.5 b \\
(11.5)\end{array}$ & $\begin{array}{c}281.1 \mathrm{a} \\
(42.9)\end{array}$ & $\begin{array}{c}216.1 \mathrm{a} \\
(42.9)\end{array}$ \\
\hline Seed mass (g (100 seeds) $\left.)^{-1}\right)$ & $\begin{array}{l}15.5 a \\
(0.40)\end{array}$ & $\begin{array}{c}14.4 a b \\
(0.40)\end{array}$ & $\begin{array}{l}14.2 \mathrm{~b} \\
(0.40)\end{array}$ & $\begin{array}{l}15.0 \mathrm{a} \\
(0.38)\end{array}$ & $\begin{array}{l}13.0 \mathrm{~b} \\
(0.38)\end{array}$ & $\begin{array}{l}15.5 a \\
(0.55)\end{array}$ & $\begin{array}{l}13.2 \mathrm{~b} \\
(0.55)\end{array}$ \\
\hline
\end{tabular}

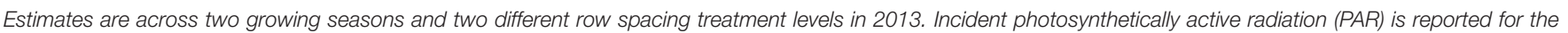

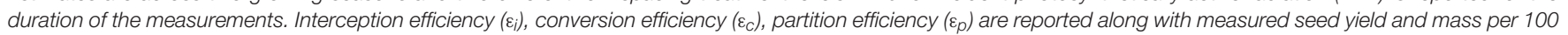

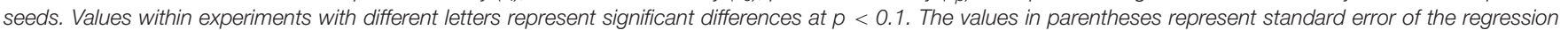

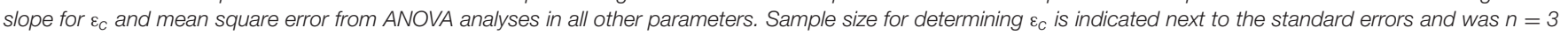
for all other parameters.

In the previous study where $A_{\mathrm{can}}$ and yields were greater in Y11y11 compared to WT, water was not limiting due to irrigation (Pettigrew et al., 1989), suggesting that these specific mutations causing chl deficiency may limit productivity in times of even moderate water stress. Although rice chl mutants with greater $g_{\mathrm{s}}$ resulted in higher yields when grown at a higher planting density, the authors do not report any water limitations. Further assessments of chl-deficient crops may need to incorporate tests of efficiency and productivity in non-optimal field conditions while maintaining or improving WUE.

The results of this study suggest that soybean overinvest in chl; thus, chl reduction represents an opportunity to reinvest nitrogen from pigment-proteins into rate limiting photosynthetic enzymes that could increase photosynthetic capacity (i.e., $V_{c, \max }$ and $J_{\max }$ ). However, nitrogen reallocation was not realized to any significant extent in these mutants. For example, a study by Evans and Poorter (2001) showed that 12.9\% of leaf organic nitrogen was associated with pigment-protein complexes and $21.6 \%$ was associated with Rubisco in plants grown at high light. Therefore, if pigment-proteins were reduced by $50 \%$ and all of the nitrogen associated with pigment-proteins was reallocated to
Rubisco, carboxylation capacity could potentially increase by up to $30 \%$. However, across both seasons, Y11y11 $V_{\mathrm{c} \text {, max }}$ increased $<5 \%$ compared to WT (Table 2 ). $J_{\max }$ only increased by $3 \%$ in 2012 and $7 \%$ in 2013 in Y11y11 compared to WT (Table 2). Therefore, further intervention would be required to redirect nitrogen savings from reduced investment in pigment-proteins in low-chl plants to the most beneficial targets for increasing photosynthesis (Zhu et al., 2007).

\section{CONCLUSION}

This study demonstrated early season benefits of reduced chl content on leaf photosynthetic efficiency and capacity. However, the effects of reduced chl were confounded with leaf properties and greater $g_{s}$ in this study and a similar study in rice. Further analyses will be needed to parse out the impacts of chl reductions on leaf structure, $g_{s}$, and $A_{\text {leaf }}$. The mutants used in this study, although relatively robust in optimal field conditions, captured less light early in the growing season and used water less efficiently, which may have impaired the effects of 
reduced chl during the drought conditions experienced in both growing seasons. Despite the pleiotropic effects of the mutations, limitations to biomass accumulation and yield were minimal, signifying an overinvestment in chl in dark-green soybean.

As evident from these results, the methods of obtaining and maintaining optimal chl concentrations require further consideration. Optimizing chl concentration within the canopy and throughout the season is required to reduce wasted light early in the season via transmission to the soil and later in the season as reflected light from the top of the canopy while maintaining a more even light distribution within the canopy. Additionally, it is crucial to identify and utilize targets that eliminate the pleiotropic effects, such as greater water loss and photooxidative effects, that can accompany many chl biosynthesis mutations. Lastly, nitrogen reinvestment will need optimization to maximize nitrogen use efficiency in low-chl plants. This suggests that directed approaches, such as transgenic technology, are required for greater benefits of reduced chl on $A_{\text {can }}, \varepsilon_{\mathrm{c}}$, and yield.

\section{AUTHOR CONTRIBUTIONS}

All authors participated conceiving and designing the research. $\mathrm{RS}, \mathrm{AV}$, and $\mathrm{CB}$ performed the research. RS and AV analyzed the data. RS and DO wrote the article, which was reviewed by all other authors.

\section{REFERENCES}

Ainsworth, E. A., and Ort, D. R. (2010). How do we improve crop production in a warming world? Plant Physiol. 154, 526-530. doi: 10.1104/pp.110.161349

Allen, J. F., and Forsberg, J. (2001). Molecular recognition in thylakoid structure and function. Trends Plant Sci. 6, 317-326. doi: 10.1016/S1360-1385(01) 02010-6

Amthor, J. S., Mitchell, R. J., Runion, G. B., Rogers, H. H., Prior, S. A., and Wood, C. W. (1994). Energy content, construction cost and phytomass accumulation of Glycine $\max$ (L.) Merr. and Sorghum bicolor (L.) Moench grown in elevated $\mathrm{CO}_{2}$ in the field. New Phytol. 128, 443-450. doi: 10.1111/j.1469-8137.1994. tb02990.x

Angel, J. (2009). The Water and Atmospheric Resources Monitoring Program. Urbana, IL: University of Illinois at Urbana-Champaign.

Austin, R., Bingham, J., Blackwell, R., Evans, L., Ford, M., Morgan, C., et al. (1980). Genetic improvements in winter wheat yields since 1900 and associated physiological changes. J. Agric. Sci. 94, 675-689. doi: 10.1017/ S0021859600028665

Baker, N. R. (2008). Chlorophyll fluorescence: a probe of photosynthesis in vivo. Annu. Rev. Plant Biol. 59, 89-113. doi: 10.1146/annurev.arplant.59.032607. 092759

Baldocchi, D. D., Verma, S. B., and Rosenberg, N. J. (1985). Water use efficiency in a soybean field: influence of plant water stress. Agric. For. Meteorol. 34, 53-65. doi: 10.1016/0168-1923(85)90054-1

Benedict, C. R., McCree, K. J., and Kohel, R. J. (1972). High photosynthetic rate of a chlorophyll mutant of cotton. Plant Physiol. 49, 968-971. doi: 10.1104/pp.49. 6.968

Bugbee, B. G., and Monje, O. (1992). The limits of crop productivity. Bioscience 42, 494-502. doi: 10.2307/1311879

Campbell, B. W., Mani, D., Curtin, S. J., Slattery, R. A., Michno, J.-M., Ort, D. R., et al. (2015). Identical substitutions in magnesium chelatase paralogs result in chlorophyll deficient soybean mutants. G3 (Bethesda) 5, 123-131. doi: 10.1534/ g3.114.015255

\section{FUNDING}

Funding was provided in part via subcontract by the Bill and Melinda Gates Foundation (OPP1060461) titled 'RIPE-Realizing Increased Photosynthetic Efficiency for Sustainable Increases in Crop Yield' and by the USDA-ARS.

\section{ACKNOWLEDGMENTS}

We would like to thank the following people for their invaluable assistance with field operations, experimental setup, measurements, and sampling: Elizabeth Ainsworth, Beau Barber, Kristen Bishop, Colleen Cahill, Nathan Couch, Alex Crisel, David Drag, Pablo Ortiz-Fenton, Sharon Gray, Aleel Grennan, Edward Hseih, Bob Koester, Courtney Leisner, Anna Locke, Jesse Miller, Anna Molineaux, Chris Montes, Abbie Peterson, Kannan Puthuval, David Rosenthal, John Spiekerman, Kaitlin Togliatti, Berkley Walker, Craig Yendrek, and Morgan Zenner. We also thank Dr. Randy Nelson for access to the soybean seed.

\section{SUPPLEMENTARY MATERIAL}

The Supplementary Material for this article can be found online at: http://journal.frontiersin.org/article/10.3389/fpls.2017.00549/ full\#supplementary-material

Campbell, G. S., and Norman, J. M. (1998). "The light environment of plant canopies," in An Introduction to Environmental Biophysics, (New York, NY: Springer-Verlag), 247-278. doi: 10.1007/978-1-4612-1626-1_15

Dermody, O., Long, S. P., McConnaughay, K., and DeLucia, E. H. (2008). How do elevated $\mathrm{CO}_{2}$ and $\mathrm{O}_{3}$ affect the interception and utilization of radiation by a soybean canopy? Glob. Chang. Biol. 14, 556-564. doi: 10.1111/j.1365-2486. 2007.01502.x

Donald, C. M. (1968). The breeding of crop ideotypes. Euphytica 17, 385-403. doi: $10.1007 / \mathrm{BF} 00056241$

Drewry, D. T., Kumar, P., and Long, S. P. (2014). Simultaneous improvement in productivity, water use, and albedo through crop structural modification. Glob. Chang. Biol. 20, 1955-1967. doi: 10.1111/gcb.12567

Du, S.-Y., Zhang, X.-F., Lu, Z., Xin, Q., Wu, Z., Jiang, T., et al. (2012). Roles of the different components of magnesium chelatase in abscisic acid signal transduction. Plant Mol. Biol. 80, 519-537. doi: 10.1007/s11103-0129965-3

Edwards, G. E., Johnson, E., Lal, A., and Krall, J. P. (1993). Quantum yields of photosystem II and photosynthesis in an aurea mutant of tobacco $\left(\mathrm{C}_{3}\right)$ and an oil yellow mutant of maize $\left(\mathrm{C}_{4}\right)$ which have high capacities for photosynthesis despite low chlorophyll contents. Plant Cell Physiol. 34, 1205-1212.

Eskins, K., Delmastro, D., and Harris, L. (1983). A comparison of pigmentprotein complexes among normal, chlorophyll-deficient and senescent soybean genotypes. Plant Physiol. 73, 51-55. doi: 10.1104/pp.73.1.51

Eskins, K., Harris, L., and Bernard, R. L. (1981). Genetic control of chloroplast pigment development in soybeans as a function of leaf and plant maturity. Plant Physiol. 67, 759-762. doi: 10.1104/pp.67.4.759

Estill, K., Delaney, R. H., Smith, W. K., and Ditterline, R. L. (1991). Water relations and productivity of alfalfa leaf chlorophyll variants. Crop Sci. 31, 1229-1233. doi: 10.2135/cropsci1991.0011183X003100050030x

Evans, J. R., and Poorter, H. (2001). Photosynthetic acclimation of plants to growth irradiance: the relative importance of specific leaf area and nitrogen partitioning in maximizing carbon gain. Plant Cell Environ. 24, 755-767. doi: 10.1046/j.1365-3040.2001.00724.x 
Evans, J. R., and Vogelmann, T. C. (2003). Profiles of 14C fixation through spinach leaves in relation to light absorption and photosynthetic capacity. Plant Cell Environ. 26, 547-560. doi: 10.1046/j.1365-3040.2003.00985.x

Evans, L. T. (1993). Crop Evolution, Adaptation, and Yield. Cambridge: Cambridge University Press.

Evans, L. T., and Fischer, R. A. (1999). Yield potential: its definition, measurement, and significance. Crop Sci. 39, 1544-1551. doi: 10.2135/cropsci1999.3961544x

FAO (2012). Food and Agricultural Commodities Production. Rome: FAO.

Farquhar, G. D., and Richards, R. A. (1984). Isotopic composition of plant carbon correlates with water-use efficiency of wheat genotypes. Aust. J. Plant Physiol. 11, 539-552. doi: 10.1071/PP9840539

Fehr, W., Caviness, C., Burmood, D. T., and Pennington, J. S. (1971). Stage of development descriptions for soybeans, Glycine max (L.) Merr. Crop Sci. 11, 929-931. doi: 10.2135/cropsci1971.0011183X001100060051x

Gamon, J. A., and Pearcy, R. W. (1989). Leaf movement, stress avoidance and photosynthesis in Vitis californica. Oecologia 79, 475-481. doi: 10.1007/ BF00378664

Ghirardi, M. L., and Melis, A. (1988). Chlorophyll $b$ deficiency in soybean mutants. I. Effects on photosystem stoichiometry and chlorophyll antenna size. Biochim. Biophys. Acta 932, 130-137. doi: 10.1016/0005-2728(88)90147-8

Gillespie, K. M., Xu, F., Richter, K. T., McGrath, J. M., Markelz, R. J. C., Ort, D. R., et al. (2012). Greater antioxidant and respiratory metabolism in field-grown soybean exposed to elevated $\mathrm{O}_{3}$ under both ambient and elevated $\mathrm{CO}_{2}$. Plant Cell Environ. 35, 169-184. doi: 10.1111/j.1365-3040.2011.02427.x

Gu, J., Zhou, Z., Li, Z., Chen, Y., Wang, Z., and Zhang, H. (2017). Rice (Oryza sativa L.) with reduced chlorophyll content exhibit higher photosynthetic rate and efficiency, improved canopy light distribution, and greater yields than normally pigmented plants. Field Crop Res. 200, 58-70. doi: 10.1016/j.fcr.2016. 10.008

Habash, D. Z., Genty, B., and Baker, N. R. (1994). The consequences of chlorophyll deficiency for photosynthetic light use efficiency in a single nuclear gene mutation of cowpea. Photosynth. Res. 42, 17-25. doi: 10.1007/BF0001 9054

Hay, R. (1995). Harvest index: a review of its use in plant breeding and crop physiology. Ann. Appl. Biol. 126, 197-216. doi: 10.1111/j.1744-7348.1995. tb05015.x

Hay, R., and Porter, J. (2006). The Physiology of Crop Yield. Oxford: Blackwell Publishing.

Highkin, H. R., Boardman, N. K., and Goodchild, D. J. (1969). Photosynthetic studies on a pea mutant deficient in chlorophyll. Plant Physiol. 44, 1310-1320. doi: 10.1104/pp.44.9.1310

Hussain, M. Z., Vanloocke, A., Siebers, M. H., Ruiz-Vera, U. M., Markelz, R. J. C., Leakey, A. D. B., et al. (2013). Future carbon dioxide concentration decreases canopy evapotranspiration and soil water depletion by field-grown maize. Glob. Chang. Biol. 19, 1572-1584. doi: 10.1111/gcb.12155

Khush, G. S. (1995). Breaking the yield frontier of rice. GeoJournal 35, 329-332. doi: 10.1007/BF00989140

Kirst, H., Gabilly, S. T., Niyogi, K. K., Lemaux, P. G., and Melis, A. (2017). Photosynthetic antenna engineering to improve crop yields. Planta doi: 10.1007/s00425-017-2659-y [Epub ahead of print].

Koester, R. P., Skoneczka, J. A., Cary, T. R., Diers, B. W., and Ainsworth, E. A. (2014). Historical gains in soybean (Glycine max Merr.) seed yield are driven by linear increases in light interception, energy conversion, and partitioning efficiencies. J. Exp. Bot. 65, 3311-3321. doi: 10.1093/jxb/eru187

Kok, B. (1948). A critical consideration of the quantum yield of Chlorella photosynthesis. Enzymologia 13, 1-56.

Kosourov, S. N., Ghirardi, M. L., and Seibert, M. (2011). A truncated antenna mutant of Chlamydomonas reinhardtii can produce more hydrogen than the parental strain. Int. J. Hydrogen Energy 36, 2044-2048. doi: 10.1016/j.ijhydene. 2010.10.041

Leverenz, J. W., Oqtaist, G., and Wingsle, G. (1992). Photosynthesis and photointiibition in leaves of chlorophyll b-less barley in relation to absorbed light. Physiol. Plant. 85, 495-502. doi: 10.1111/j.1399-3054.1992. tb05817.x

Li, Y., Ren, B., Gao, L., Ding, L., Jiang, D., Xu, X., et al. (2013). Less chlorophyll does not necessarily restrain light capture ability and photosynthesis in a chlorophyll-deficient rice mutant. J. Agron. Crop Sci. 199, 49-56. doi: 10.1111/j. 1439-037X.2012.00519.x
Lichtenthaler, H. (1987). Chlorophylls and carotenoids: pigments of photosynthetic biomembranes. Methods Enzymol. 148, 350-382. doi: 10.1016/0076-6879(87)48036-1

Lobell, D. B., Cassman, K. G., and Field, C. B. (2009). Crop yield gaps: their importance, magnitudes, and causes. Annu. Rev. Environ. Resour. 34, 179-204. doi: 10.1146/annurev.environ.041008.093740

Long, S. P., and Bernacchi, C. J. (2003). Gas exchange measurements, what can they tell us about the underlying limitations to photosynthesis? Procedures and sources of error. J. Exp. Bot. 54, 2393-2401. doi: 10.1093/jxb/erg262

Long, S. P., Zhu, X.-G., Naidu, S. L., and Ort, D. R. (2006). Can improvement in photosynthesis increase crop yields? Plant Cell Environ. 29, 315-330. doi: 10.1111/j.1365-3040.2005.01493.x

Luquez, V. M., Guiamet, J. J., and Montaldi, E. R. (1997). Net photosynthetic and transpiration rates in a chlorophyll-deficient isoline of soybean under wellwatered and drought conditions. Photosynthetica 34, 125-131. doi: 10.1023/A: 1006824120129

Melis, A. (1999). Photosystem-II damage and repair cycle in chloroplasts: what modulates the rate of photodamage in vivo? Trends Plant Sci. 4, 130-135. doi: 10.1016/S1360-1385(99)01387-4

Melis, A. (2009). Solar energy conversion efficiencies in photosynthesis: minimizing the chlorophyll antennae to maximize efficiency. Plant Sci. 177, 272-280. doi: 10.1016/j.plantsci.2009.06.005

Mitra, M., and Melis, A. (2008). Optical properties of microalgae for enhanced biofuels production. Opt. Express 16, 21807-21820. doi: 10.1364/OE.16.021807

Monteith, J. L. (1965). Radiation and crops. Exp. Agric. 1, 241-251. doi: 10.1017/ S0014479700021529

Monteith, J. L. (1972). Solar radiation and productivity in tropical ecosystems. J. Appl. Ecol. 9, 747-766. doi: 10.2307/2401901

Monteith, J. L. (1977). Climate and the efficiency of crop production in Britain. Philos. Trans. R. Soc. Lond. B Biol. Sci. 281, 277-294. doi: 10.1098/rstb.1977.0140

Niinemets, Ü (1999). Components of leaf dry mass per area - thickness and density - alter leaf photosynthetic capacity in reverse directions in woody plants. New Phytol. 144, 35-47. doi: 10.1046/j.1469-8137.1999.00466.x

Niyogi, K. K. (1999). Photoprotection revisited: genetic and molecular approaches. Annu. Rev. Plant Physiol. Plant Mol. Biol. 50, 333-359. doi: 10.1146/annurev. arplant.50.1.333

Oguchi, R., Douwstra, P., Fujita, T., Chow, W. S., and Terashima, I. (2011). Intraleaf gradients of photoinhibition induced by different color lights: implications for the dual mechanisms of photoinhibition and for the application of conventional chlorophyll fluorometers. New Phytol. 191, 146-159. doi: 10.1111/ j.1469-8137.2011.03669.x

Ort, D. R. (2001). When there is too much light. Plant Physiol. 125, 29-32. doi: $10.1104 / p p \cdot 125.1 .29$

Ort, D. R., and Long, S. P. (2014). Limits on yields in the Corn Belt. Science 344, 484-485. doi: 10.1126/science. 1253884

Ort, D. R., Merchant, S. S., Alric, J., Barkan, A., Blankenship, R. E., Bock, R., et al. (2015). Redesigning photosynthesis to sustainably meet global food and bioenergy demand. Proc. Natl. Acad. Sci. U.S.A. 112, 8529-8536. doi: 10.1073/ pnas. 1424031112

Ort, D. R., Zhu, X., and Melis, A. (2011). Optimizing antenna size to maximize photosynthetic efficiency. Plant Physiol. 155, 79-85. doi: 10.1104/pp.110.165886

Pettigrew, W. T., Hesketh, D., Peters, D. B., and Woolley, T. (1989). Characterization of canopy photosynthesis of chlorophyll-deficient soybean isolines. Crop Sci. 29, 1024-1028. doi: 10.2135/cropsci1989. 0011183X002900040040x

Polle, J. E. W., Kanakagiri, S., Jin, E., Masuda, T., and Melis, A. (2002). Truncated chlorophyll antenna size of the photosystems-a practical method to improve microalgal productivity and hydrogen production in mass culture. Int. J. Hydrogen Energy 27, 1257-1264. doi: 10.1016/S0360-3199(02)00116-7

Porra, R., Thompson, W., and Kriedemann, P. (1989). Determination of accurate extinctions coefficients and simultaneous equations for assaying chlorophylls $a$ and $b$ extracted with four different solvents: verification of the concentration of chlorophyll standards by atomic absorption spectrosc. Biochim. Biophys. Acta 975, 384-394. doi: 10.1016/S0005-2728(89)80347-0

Prasad, P. V. V., Boote, K. J., Allen, L. H. Jr., Sheehy, J. E., and Thomas, J. M. G. (2006). Species, ecotype and cultivar differences in spikelet fertility and harvest index of rice in response to high temperature stress. Field Crop Res. 95, 398-411. doi: $10.1016 /$ j.fcr.2005.04.008 
Prater, M. R., Obrist, D., Arnone, J. A., and DeLucia, E. H. (2006). Net carbon exchange and evapotranspiration in postfire and intact sagebrush communities in the Great Basin. Oecologia 146, 595-607. doi: 10.1007/s00442-0050231-0

Rogers, A., Allen, D. J., Davey, P. A., Morgan, P. B., Ainsworth, E. A., Bernacchi, C. J., et al. (2004). Leaf photosynthesis and carbohydrate dynamics of soybeans grown throughout their life-cycle under Free-Air Carbon dioxide Enrichment. Plant Cell Environ. 27, 449-458. doi: 10.1111/j.1365-3040.2004.01163.x

Sinclair, T. R. (1998). Historical changes in harvest index and crop nitrogen accumulation. Crop Sci. 38, 638-643. doi: 10.2135/cropsci1998. 0011183X003800030002x

Slattery, R. A., Ainsworth, E. A., and Ort, D. R. (2013). A meta-analysis of responses of canopy photosynthetic conversion efficiency to environmental factors reveals major causes of yield gap. J. Exp. Bot. 64, 3723-3733. doi: 10.1093/jxb/ ert207

Slattery, R. A., Grennan, A. K., Sivaguru, M., Sozzani, R., and Ort, D. R. (2016). Light sheet microscopy reveals more gradual light attenuation in light-green versus dark-green soybean leaves. J. Exp. Bot. 67, 4697-4709. doi: 10.1093/jxb/ erw246

Slattery, R. A., and Ort, D. R. (2015). Photosynthetic energy conversion efficiency: setting a baseline for gauging future improvements in important food and biofuel crops. Plant Physiol. 168, 383-392. doi: 10.1104/pp.15.00066

Smil, V. (1999). Crop residues: agriculture's largest harvest - crop residues incorporate more than half of the world's agricultural phytomass. Bioscience 49, 299-308. doi: 10.2307/1313613

Srinivasan, V., Kumar, P., and Long, S. P. (2016). Decreasing, not increasing, leaf area will raise crop yields under global atmospheric change. Glob. Chang. Biol. 23, 1626-1635. doi: $10.1111 /$ gcb.13526

Tsuzuki, T., Takahashi, K., Inoue, S., Okigaki, Y., Tomiyama, M., Hossain, M. A., et al. (2011). Mg-chelatase $\mathrm{H}$ subunit affects ABA signaling in stomatal guard cells, but is not an ABA receptor in Arabidopsis thaliana. J. Plant Res. 124, 527-538. doi: 10.1007/s10265-011-0426-x

Vogelmann, T. C., and Evans, J. R. (2002). Profiles of light absorption and chlorophyll within spinach. Plant Cell Environ. 25, 1313-1323. doi: 10.1046/j. 1365-3040.2002.00910.x

Xu, D., Chen, X. M., Zhang, L. X., Wang, R. F., and Hesketh, J. D. (1993). Leaf photosynthesis and chlorophyll fluorescence in a chlorophyll-deficient soybean mutant. Photosynthetica 29, 103-112.

Zhu, X.-G., de Sturler, E., and Long, S. P. (2007). Optimizing the distribution of resources between enzymes of carbon metabolism can dramatically increase photosynthetic rate: a numerical simulation using an evolutionary algorithm. Plant Physiol. 145, 513-526. doi: 10.1104/pp.107.103713

Zhu, X.-G., Long, S. P., and Ort, D. R. (2008). What is the maximum efficiency with which photosynthesis can convert solar energy into biomass? Curr. Opin. Biotechnol. 19, 153-159. doi: 10.1016/j.copbio.2008.02.004

Zhu, X.-G., Long, S. P., and Ort, D. R. (2010). Improving photosynthetic efficiency for greater yield. Annu. Rev. Plant Biol. 61, 235-261. doi: 10.1146/annurevarplant-042809-112206

Conflict of Interest Statement: The authors declare that the research was conducted in the absence of any commercial or financial relationships that could be construed as a potential conflict of interest.

Copyright (C) 2017 Slattery, VanLoocke, Bernacchi, Zhu and Ort. This is an openaccess article distributed under the terms of the Creative Commons Attribution License (CC BY). The use, distribution or reproduction in other forums is permitted, provided the original author(s) or licensor are credited and that the original publication in this journal is cited, in accordance with accepted academic practice. No use, distribution or reproduction is permitted which does not comply with these terms. 